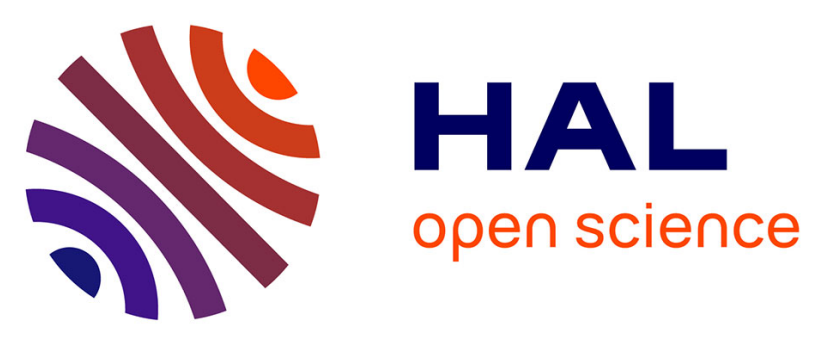

\title{
A new method for incorporating polyethyleneimine (PEI) in algal beads: High stability as sorbent for palladium recovery and supported catalyst for nitrophenol hydrogenation
}

Shengye Wang, Thierry Vincent, Catherine Faur, Enrique

Rodríguez-Castellón, Eric Guibal

\section{To cite this version:}

Shengye Wang, Thierry Vincent, Catherine Faur, Enrique Rodríguez-Castellón, Eric Guibal. A new method for incorporating polyethyleneimine (PEI) in algal beads: High stability as sorbent for palladium recovery and supported catalyst for nitrophenol hydrogenation. Materials Chemistry and Physics, 2019, 221, pp.144 - 155. 10.1016/j.matchemphys.2018.09.021 . hal-01937653

\section{HAL Id: hal-01937653 \\ https://hal.umontpellier.fr/hal-01937653}

Submitted on 4 Feb 2020

HAL is a multi-disciplinary open access archive for the deposit and dissemination of scientific research documents, whether they are published or not. The documents may come from teaching and research institutions in France or abroad, or from public or private research centers.
L'archive ouverte pluridisciplinaire HAL, est destinée au dépôt et à la diffusion de documents scientifiques de niveau recherche, publiés ou non, émanant des établissements d'enseignement et de recherche français ou étrangers, des laboratoires publics ou privés. 


\title{
A new method for incorporating polyethyleneimine (PEI) in algal beads: High stability as sorbent for palladium recovery and supported catalyst for nitrophenol hydrogenation
}

\author{
Shengye Wang ${ }^{\mathrm{a}, * *}$, Thierry Vincent ${ }^{\mathrm{a}}$, Catherine Faur ${ }^{\mathrm{b}}$, Enrique Rodríguez-Castellón ${ }^{\mathrm{c}}$, \\ Eric Guibal ${ }^{\mathrm{a}, *}$ \\ ${ }^{a}$ C2MA, IMT Mines Ales, Univ Montpellier, Ales, France \\ ${ }^{\mathrm{b}}$ IEM, Institut Européen des Membranes, Univ Montpellier, CNRS, ENSCM, Montpellier, France \\ ${ }^{c}$ Departamento de Química Inorgánica, Facultad de Ciencias, Universidad de Málaga, E-29071, Málaga, Spain
}

\section{H I G H L I G H T S}

- Pd(II) sorbed onto PEI-homogeneous or -heterogeneous alginate beads.

- After in situ reduction Pd catalysts are tested for 3-nitrophenol hydrogenation.

- Pd aggregates are not formed on homogeneous beads contrary to heterogeneous beads.

- $\operatorname{Pd}(0)$ loaded on homogeneous beads is more stable when reused for 3-NP reduction.
G R A P H I C A L A B S T R A C T

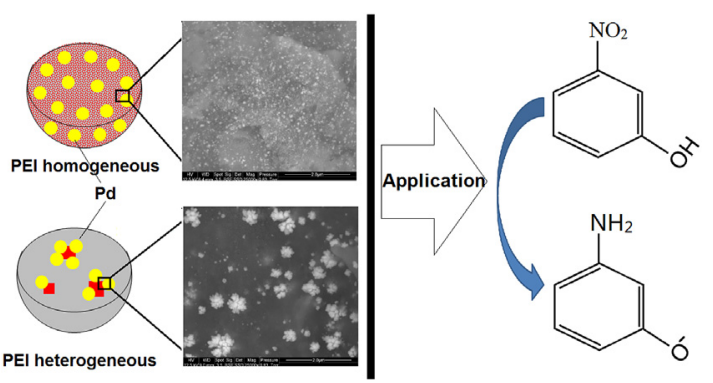

\section{A B S T R A C T}

The incorporation of glutaraldehyde crosslinked polyethylenimine (PEI) in algal beads (ABA/PEI) increases its Pd(II) sorption capacity. However, the large size of dispersed agglomerates introduces limitations of sorption performance in terms of availability and accessibility of reactive groups. The homogeneous incorporation of PEI in alginate/algal mixture prior to inotropic gelation and glutaraldehyde crosslinking (HABA/PEI) improves sorption performance: HABA/PEI beads have a higher maximum sorption capacity $\left(1.49 \pm 0.02 \mathrm{mmol} \mathrm{g}^{-1}\right)$ than ABA/PEI $\left(1.13 \pm 0.03 \mathrm{mmol} \mathrm{g}^{-1}\right)$, probably due to more uniform dispersion of PEI in HABA/PEI beads. The comparison of 5 consecutive cycles of sorption-desorption shows that HABA/PEI beads are physically stable with no mass loss, while ABA/PEI bead loses up to $30 \%$ of its weight. The potential of these materials as precursors for the synthesis of supported catalysts has been investigated. Pd(II) sorbed on ABA/PEI and HABA/ $\mathrm{PEI}$ has been reduced to $\mathrm{Pd}(0)$ using hydrazine hydrate or hydrogen gas (generated in situ). A simple hydrogenation reaction of 3-nitrophenol (with sodium formate as hydrogen donor) was tested for comparing their catalytic properties. Catalytic tests show that HABA catalyst exhibits similar catalytic activity, but better stability and reusability compared with ABA catalyst. Their rate constants are lower than conventional nanostructured catalysts, probably due to intra-diffusion limitation.

\footnotetext{
* Corresponding author.

** Corresponding author.

E-mail addresses: Shengye.Wang@mines-ales.fr (S. Wang), Thierry.Vincent@mines-ales.fr (T. Vincent), Catherine.Faur@umontpellier.fr (C. Faur), castellon@uma.es (E. Rodríguez-Castellón), Eric.Guibal@mines-ales.fr (E. Guibal).
} 


\section{Introduction}

Precious metals (PGMs), including Pt, Ru, Rh, Ir and Pd, are considered dominant active catalytic materials for hydrocarbon reforming. The use of Pd nanoparticles in catalysis is of great interest, attributed to the low loadings of $0.001-0.1 \mathrm{~mol} \%$ requirements for catalytic activity and improved activity over the bulk metal [1]. The major drawback of Pd for catalytic applications is its high cost and thus, recovering such metal from waste sources should prove lucrative. The use of leaching has been successful in extracting Pd from spent catalysts; nevertheless, the separation of such metal from the leaching liquor remains a challenge, especially when the metal concentration in the leachate is low. Sorption technique is known as an economical and effective process for Pd recovery from acid leaching liquors. Several sorbents have been tested including activated carbon [2], modified chitosan [3], alginate beads [4], algal foams [5], etc. The immobilization of catalyst particles upon biosorbents has been shown to be a promising way to produce active catalysts as a potential alternative to traditional homogenous catalysts [6-8]. Vincent and Guibal [9] successfully prepared chitosansupported palladium catalyst through two steps: sorption and chemical reduction and found it efficient for chromate reduction. Dong et al. [10] investigated the use of $\mathrm{Au}$ or Pd nanoparticles supported on magnetic porous carbon (MPC) composite for 4-nitrophenol reduction and their results show that the supported catalysts exhibited comparable or better catalytic activity than most of the reported catalysts. Palladium nanoparticles over graphite oxide and carbon nanotubes, reported by Dongil et al. [11], present good reusability. These supported catalysts use green and economical support material and metals can be recycled and reused from various waste sources. After use, metals immobilized on such supports can be recovered and loaded again onto the supports to make another batch of catalyst.

Algae are readily available and easily got from the ocean. Their affinity for metal ions has been reported by many studies [12-14]. Their ready availability and low cost make them also interesting to be used as cost-effective and environmental friendly supports. On the other side, polyethyleneimine (PEI), a synthetic polymer, has been widely used in recovering Pd(II) from acid matrix due to its abundant amine groups. Recently, glutaraldehyde-crosslinked polyethyleneimine (PEIGA) powders were incorporated into a green material (brown algal beads or foams) and the composites were reported to be efficient for Pd (II) sorption $[5,15]$ (the so-called ABA/PEI sorbent). However, the PEIGA particles incorporated in beads may be easily released under strong shaking or when applied in complex systems with an excess of ions such as $\mathrm{K}(\mathrm{I})$ or $\mathrm{Na}(\mathrm{I})$ (due to the formation of soluble Na-alginate or K-alginate, etc.) and/or at higher $\mathrm{pH}$. This not only limits their application as sorbents for Pd(II) recovery from leaching liquors but also may cause loss of precious metals when used as supported catalysts. In this study, another easier way to produce more stable composite beads is proposed, associating PEI-GA and a brown alga (L. digitata). Specifically, PEI solution is pre-mixed with alga and alginate. The mixture was dropped into a solution that contains both $\mathrm{CaCl}_{2}$ and GA. In this case, algal beads constitute the support for PEI-GA. At the same time, the crosslinking between PEI and GA, in turn, improves the stability of the composites (HABA/PEI). The sorption efficiency for $\mathrm{Pd}(\mathrm{II})$ and the stability in different concentrations of $\mathrm{NaCl}$ matrices at different $\mathrm{pH}$ values were compared. Uptake kinetics and sorption isotherms were also compared. The stability of the sorbents was tested along 5 successive cycles of sorption and desorption. Moreover, as a first step to evaluate the feasibility of applying the Pd-loaded beads as precursors of supported catalysts, the metal-loaded sorbents were submitted to a reduction process and thereafter their catalytic activity was tested by a simple reaction: the reduction of 3-nitrophenol (3-NP) in the presence of sodium formate (hydrogen donor). Obviously, this simple hydrogenation reaction has no commercial interest; however, this model reaction, which is easily carried out, is frequently used for the pre-characterization of heterogeneous hydrogenation catalysts [16-18].

\section{Experimental}

\subsection{Materials}

The brown algal biomass, L. digitata, was supplied by SETALG (Pleubian, France). It was washed, dried, grinded, and sieved $(<250 \mu \mathrm{m})$ before use. Alginate (Manugel GMB) was purchased from FMC BioPolymer (Cork, Ireland).

Branched polyethyleneimine (PEI, $50 \%(\mathrm{w} / \mathrm{w})$ in water) and glutaraldehyde $(\mathrm{GA}, 50 \%(\mathrm{w} / \mathrm{w})$ in water) were obtained from SigmaAldrich (Taufkirchen, Germany). Sodium carbonate, formic acid and calcium chloride were supplied by Chem-Lab NV (Zedelgem, Belgium). Palladium(II) chloride was purchased from R.D. H (Seelze, Germany). The stock solution was prepared by dissolving $1 \mathrm{~g}$ of palladium chloride into $1.1 \mathrm{M} \mathrm{HCl}$ solution.

\subsection{Preparation of the beads}

Fig. S1 (see Supplementary Material Section) reports the different steps in the preparation of the sorbents. First, $18.75 \mathrm{~g}$ of $\mathrm{L}$. digitata were added into $750 \mathrm{~mL}$ of $1 \% \mathrm{Na}_{2} \mathrm{CO}_{3}$. The mixture was maintained at $50{ }^{\circ} \mathrm{C}$ for $24 \mathrm{~h}$. To make the composites more stable, a certain amount of alginate was added. Specifically, the mixture was mixed with $250 \mathrm{~mL}$ of $4 \%$ alginate solution and then divided into 2 equal parts. One part was added with $5 \mathrm{~mL}$ of PEI solution $(50 \%, \mathrm{w} / \mathrm{w})$ and then dropped into a solution containing $10 \% \mathrm{CaCl}_{2}$ and $5 \mathrm{~mL}$ of $\mathrm{GA}(50 \%, \mathrm{w} / \mathrm{w})$, while the other part was added with PEI-GA powder (described as below) and dropped into a solution that only contains $10 \% \mathrm{CaCl}_{2}$. The beads obtained by these two methods are named HABA/PEI and ABA/PEI, respectively.

PEI-GA powder was prepared by: (a) dissolving $5 \mathrm{~g}$ of PEI (50\%) into $20 \mathrm{~mL}$ water, and (b) crosslinking with $5 \mathrm{~g}$ of GA solution (50\%). After maintaining at room temperature over $24 \mathrm{~h}$, solid PEI-GA was obtained and filtrated. After rinsing, the powder was freeze-dried.

\subsection{Characterization}

Scanning electron microscopy (SEM) observations and SEM-EDX (SEM coupled with energy dispersive X-ray diffraction analysis) analyses were performed using an environmental scanning electron microscope Quanta FEG 200 (FEI France, Thermo Fisher Scientific, Mérignac, France), equipped with an Oxford Inca 350 energy dispersive X-ray micro-analyzer (Oxford Instruments France, Saclay, France).

FT-IR spectrometry analysis was performed in the range $4000-400 \mathrm{~cm}^{-1}$ using an FTIR-ATR (Attenuated Total Reflectance tool) Bruker VERTEX70 spectrometer (Bruker, Ettlingen, Germany).

The Pd(II) loaded beads used for characterization of metal-sorbent interaction were prepared by contact of $20 \mathrm{mg}$ of the sorbent with $50 \mathrm{mLPd}(\mathrm{II})$ solution $\left(\mathrm{pH}=1, \mathrm{C}_{0}=1 \mathrm{mmol} \mathrm{L}^{-1}\right)$. The beads after desorption were prepared by desorbing the above Pd(II)-loaded beads (10 mg) using $50 \mathrm{~mL}$ of $0.1 \mathrm{M} \mathrm{HCl} / 0.2 \mathrm{M}$ thiourea solution. The beads were rinsed and freeze-dried before characterization.

XPS studies were carried on a Physical Electronics spectrometer (PHI Versa Probe II Scanning XPS Microprobe, Physical Electronics, Chanhassen, MN, USA) with monochromatic X-ray Al Ka radiation $(100 \mu \mathrm{m}, 100 \mathrm{~W}, 20 \mathrm{kV}, 1486.6 \mathrm{eV})$ and a dual beam charge neutralizer. The spectrometer energy scale was calibrated using $\mathrm{Cu} 2 p_{3 / 2}, \mathrm{Ag} 3 d_{5 / 2}$, and $\mathrm{Au} 4 f_{7 / 2}$ photoelectron lines at 932.7, 368.2 and $84.0 \mathrm{eV}$, respectively. Under a constant pass energy mode at $23.5 \mathrm{eV}$ condition, the $\mathrm{Au}$ $4 f_{7 / 2}$ line was recorded with $0.73 \mathrm{eV}$ FWHM at a binding energy (BE) of $84.0 \mathrm{eV}$. Recorded spectra were always fitted using Gauss-Lorentz curves. Atomic concentration percentages of the characteristic elements of the surfaces were determined taking into account the corresponding area sensitivity factor for the different measured spectral regions. 


\subsection{Stability test}

Stability test was carried out by contacting $20 \mathrm{mg}\left(\mathrm{m}_{0}\right)$ of the beads with $50 \mathrm{~mL}$ of different concentrations of $\mathrm{NaCl}$ solutions at $\mathrm{pH} 1$ or $\mathrm{pH}$ 5. After shaking at $200 \mathrm{rpm}$ for $72 \mathrm{~h}$, the beads were passed through a 2$\mathrm{mm}$ sieve. The materials left on the sieve were collected, dried and weighted $\left(\mathrm{m}_{\mathrm{eq}}\right)$. The mass change rate was calculated as follows:

$\mathrm{R}_{\text {mass }}(\%)=\left(\mathrm{m}_{\mathrm{eq}}-\mathrm{m}_{0}\right) / \mathrm{m}_{\mathrm{eq}} * 100$

\subsection{Palladium(II) recovery}

The experiments to investigate the effect of $\mathrm{pH}$ were conducted within the initial $\mathrm{pH}$ range of $0.5-4$ with sorbent dosage of $0.25 \mathrm{~g} \mathrm{~L}^{-1}$ and contact time of $72 \mathrm{~h}$ at $20^{\circ} \mathrm{C}$. The $\mathrm{pH}$ of the solution was adjusted using $\mathrm{H}_{2} \mathrm{SO}_{4}$ or $\mathrm{NaOH}$. The initial and final values of $\mathrm{pH}$ were measured using a pH-meter Cyber scan pH 6000 (Eutech instruments, Nijkerk, The Netherlands).

Sorption isotherms were carried out by contact of the solutions containing different concentrations of $\mathrm{Pd}(\mathrm{II})$ with the sorbents for $72 \mathrm{~h}$ at $20^{\circ} \mathrm{C}$. The sorbent dosage (SD) was $0.5 \mathrm{~g} \mathrm{~L}^{-1}$ (dry weight) and initial Pd(II) concentration $\left(\mathrm{C}_{0}, \mathrm{mmol} \mathrm{Pd} \mathrm{L}^{-1}\right)$ varied between 0.05 and $2 \mathrm{mmol} \mathrm{Pd} \mathrm{L}{ }^{-1}$. The residual metal concentration $\left(\mathrm{C}_{\mathrm{eq}}, \mathrm{mmol} \mathrm{Pd} \mathrm{L}^{-1}\right)$, after filtration, was analyzed by inductively coupled plasma atomic emission spectrometry (ICP-AES, JY Activa M, Jobin-Yvon, Horiba, Longjumeau, France). The sorption capacity ( $\mathrm{q}, \mathrm{mmol} \mathrm{Pd} \mathrm{g}^{-1}$ ) was calculated by the mass balance equation: $\mathrm{q}_{\mathrm{eq}}=\left(\mathrm{C}_{0}-\mathrm{C}_{\mathrm{eq}}\right) * \mathrm{~V} / \mathrm{SD}$.

Uptake kinetics was studied with the sorbent dosage of $0.2 \mathrm{~g} \mathrm{~L}^{-1}, \mathrm{Pd}$ (II) concentration of $0.5 \mathrm{mmol} \mathrm{L}^{-1}$ and initial solution $\mathrm{pH}$ of 1 adjusted by $\mathrm{H}_{2} \mathrm{SO}_{4}$. Water samples were regularly collected and analyzed for residual metal concentration using ICP-AES.

For the study of sorbent reuse, $20 \mathrm{mg}$ of the beads were firstly contacted with $100 \mathrm{~mL}$ of $\mathrm{Pd}(\mathrm{II})$ solution. After shaking for $48 \mathrm{~h}$ at $150 \mathrm{rpm}$, the beads were washed, added with $5 \mathrm{~mL}$ of $0.1 \mathrm{M} \mathrm{HCl} / 0.2 \mathrm{M}$ thiourea (desorption agent), and maintained in a $50{ }^{\circ} \mathrm{C}$ oven without shaking for $24 \mathrm{~h}$. Then, the beads were maintained in $5 \mathrm{~mL}$ of pure water at $50^{\circ} \mathrm{C}$ oven for $24 \mathrm{~h}$ to leach out the remaining mobile Pd(II) and the desorption agent. Thereafter, the beads were washed and dried for next sorption-desorption cycle.

The speciation of palladium at different conditions was calculated by Visual MINTEQ (version 3.0, 2011, KTH, Sweden) [19]. Full experimental conditions are systematically reported in the caption of the Figures.

\subsection{Modeling of sorption isotherms and uptake kinetics}

Pseudo-first order rate equation (PFORE), pseudo-second order rate equation (PSORE) and Crank equation were used for modeling sorption kinetics, and sorption isotherms were fitted by the Langmuir and the Freundlich equations. All the equations are summarized in the Supplementary Material Section.

\subsection{Procedures for the reduction of loaded palladium(II)}

Different agents including ethanol, hydrazine, and in situ generated hydrogen (by the reaction of zinc and sulfuric acid) were compared for the reduction of loaded Pd(II). For the treatment with ethanol, $40 \mathrm{mg}$ of Pd(II)-loaded beads were added into $100 \mathrm{~mL}$ of pure ethanol and refluxed for $6 \mathrm{~h}$ at $80^{\circ} \mathrm{C}$. The reduction with hydrazine was performed by maintaining $40 \mathrm{mg}$ Pd-loaded beads in a solution $(80 \mathrm{~mL})$ containing hydrazine hydrate $(0.02 \mathrm{M})$ and $\mathrm{NaOH}(0.5 \mathrm{mM})$ at $60^{\circ} \mathrm{C}$ for $5 \mathrm{~h}$. The third method consists of adding $40 \mathrm{mg}$ of loaded sorbents and $80 \mathrm{mg}$ of zinc (fine powder) into $20 \mathrm{~mL}$ of $1 \% \mathrm{H}_{2} \mathrm{SO}_{4}$.

\subsection{Nitrophenol reduction}

Nitrophenol is reported to be easily reduced to aminophenol by $\mathrm{NaBH}_{4}$ in the presence of metals in solution [20]; the metal NPs catalyze this reaction by facilitating electron relay from the donor $\mathrm{BH}_{4}{ }^{-}$to acceptor nitrophenol to overcome the kinetic barrier. To avoid using this toxic and high-cost reagent in the water treatment process, before the experiment, a test was conducted to compare $\mathrm{NaCOOH}$ with $\mathrm{NaBH}_{4}$ for 3-NP reduction. Unless specified, 3-nitrophenol was reduced by contact of a 3 -NP solution $\left(200 \mathrm{~mL}, 50 \mathrm{mg} \mathrm{L}^{-1}\right)$ containing either $25 \mathrm{mM}$ sodium formate or $36 \mathrm{mM}$ sodium borohydride with $40 \mathrm{mg}$ (before palladium reduction) catalyst. Samples were collected and filtered before being analyzed using a UV spectrophotometer (Shimadzhu UV-160A, Kyoto, Japan) at $400 \mathrm{~nm}$ when reduced by $\mathrm{NaBH}_{4}$ [21], while when using $\mathrm{NaCOOH}$, the samples were further acidified with sulfuric acid ( $2 \mathrm{~mL}$ sample with $40 \mu \mathrm{L} 5 \% \mathrm{H}_{2} \mathrm{SO}_{4}$ ) before being analyzed at $332 \mathrm{~nm}$ [9]. The result of the test is shown in Fig. S2 in Supplementary Materials. HABA/PEI presents a slightly better catalytic performance when using $\mathrm{NaBH}_{4}$ as the hydrogen donor. However, ABA/PEI beads are completely degraded in solution containing $\mathrm{NaBH}_{4}$, which could be the explanation of their best reduction performance. The degradation of $\mathrm{ABA} / \mathrm{PEI}$ beads highly affects their recovery and reuse. Therefore, the comparison of HABA/PEI and ABA/PEI catalysts for 3-NP reduction was conducted using $\mathrm{NaCOOH}$ as the hydrogen donor. This reagent is non-toxic and can be handled and stored easily.

\subsection{Reproducibility}

In this study, selected experiments were duplicated. Average values and standard deviations were calculated. In addition, the repeatability of the synthesis procedure for both sorbents and supported catalysts were tested. Data presented in Fig. S3 (see Supplementary Material Section) show very small differences between comparable experiments, suggesting that the synthesis procedures for HABA/PEI and ABA/PEI sorbents or Pd supported catalysts are reproducible.

\section{Results and discussion}

\subsection{Characterization}

\subsubsection{SEM and SEM-EDX analysis}

The cross-section morphologies of the raw and Pd(II)-loaded beads were analyzed by SEM-EDX. SEM images of unreacted beads shown in Fig. 1 present a tighter structure for HABA/PEI than that for ABA/PEI beads. ABA/PEI beads are characterized by randomly distributed large open pores with thin internal wall, while HABA/PEI beads have a more dense and homogeneous layer at the periphery and a large hole at the center of the beads. After binding Pd(II), the PEI-GA particles loaded with $\mathrm{Pd}(\mathrm{II})$ in ABA/PEI beads become brighter. Due to its tighter structure, it is expected that the diffusion of the adsorbate into the core of HABA/PEI should be slower than into ABA/PEI beads. Indeed, the element cartographies of the beads after contacting with Pd(II) solution at different time intervals show that at $4 \mathrm{~h}$, the diffusion distance (marked with white arrows) from the outer layer towards the center of HABA/PEI beads is $0.309 \pm 0.029 \mathrm{~mm}$, while that of ABA/PEI is longer $(0.390 \pm 0.030 \mathrm{~mm})$. Moreover, the sorption of $\mathrm{Pd}(\mathrm{II})$ is roughly homogeneous in the whole mass of the sorbent for HABA/PEI beads while in the case of ABA/PEI beads, some large aggregates of metal element can be identified, probably due to the concentration of $\mathrm{Pd}(\mathrm{II})$ on the particles of PEI-GA. The distribution of $\mathrm{Cl}$ showed in Fig. S4 (Supplementary Material Section) is consistent to that of Pd, revealing that a large part of $\mathrm{Pd}(\mathrm{II})$ is taken up under the form of chlorometal complexes.

Fig. 2 shows the SEM images (magnified 38, 10000 and 25000 times) of Pd(II)-loaded beads and the catalysts (after Pd(II) reduction). It should be noted that Pd(II)-loaded beads were obtained from sorption 


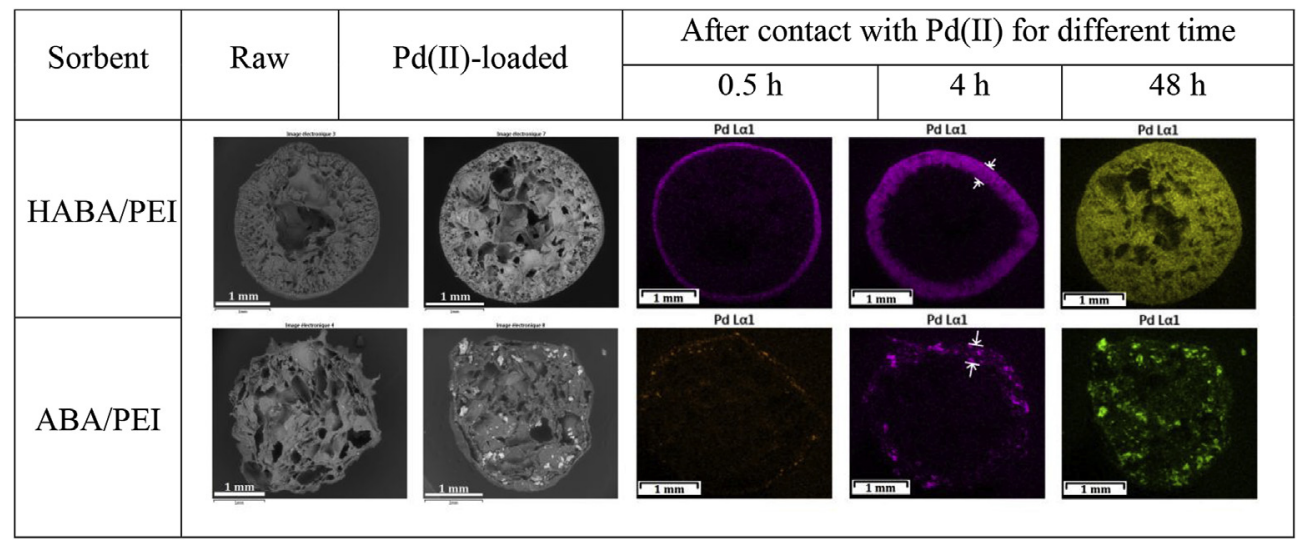

Fig. 1. SEM micrographs of the raw beads and EDX element cartographies of Pd in Pd(II)-loaded beads.

isotherm experiments with a loading amount of $1.45 \mathrm{mmol} \mathrm{Pd}^{-1}$ for

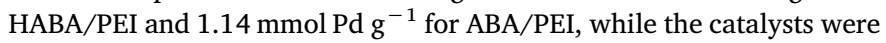
previously loaded with $1.0 \pm 0.1 \mathrm{mmol} \mathrm{Pd} \mathrm{g}^{-1}$ (for both). Since the Pd loading amount for HABA/PEI-Pd catalyst is far below its maximum sorption capacity, the center of the beads (darker region of the SEM image) is not reached by Pd(II) (verified by EDX cartography in Fig. S5, Supplementary Material Section). After magnifying the cross section of HABA/PEI beads (bright region) and Pd(II)- or Pd-loaded (after Pd(II) reduction) PEI-GA particles on ABA/PEI beads, Pd nanoparticles can be observed on both Pd(II)-reduced beads (i.e., HABA/PEI-Pd and ABA/
PEI-Pd catalysts). However, due to the concentration of Pd on PEI-GA particles, aggregates (hollow arrows) of nanoparticles (solid arrows) are observed at a magnification of $25,000 \times$ on ABA/PEI-Pd. On the opposite hand, for HABA/PEI catalyst, a uniform dispersion of PEI helps in homogenously distributing $\mathrm{Pd}(\mathrm{II})$ and thus forms individual nanoparticles. This phenomenon leads to the expectation of a better catalytic activity of Pd nanoparticles supported on HABA/ $\underline{\mathrm{PEI}}$ than $\underline{\mathrm{ABA}} / \underline{\mathrm{PEI}}$ beads, since the aggregation of nanoparticles might lead to the reduction in the reaction rate [22].

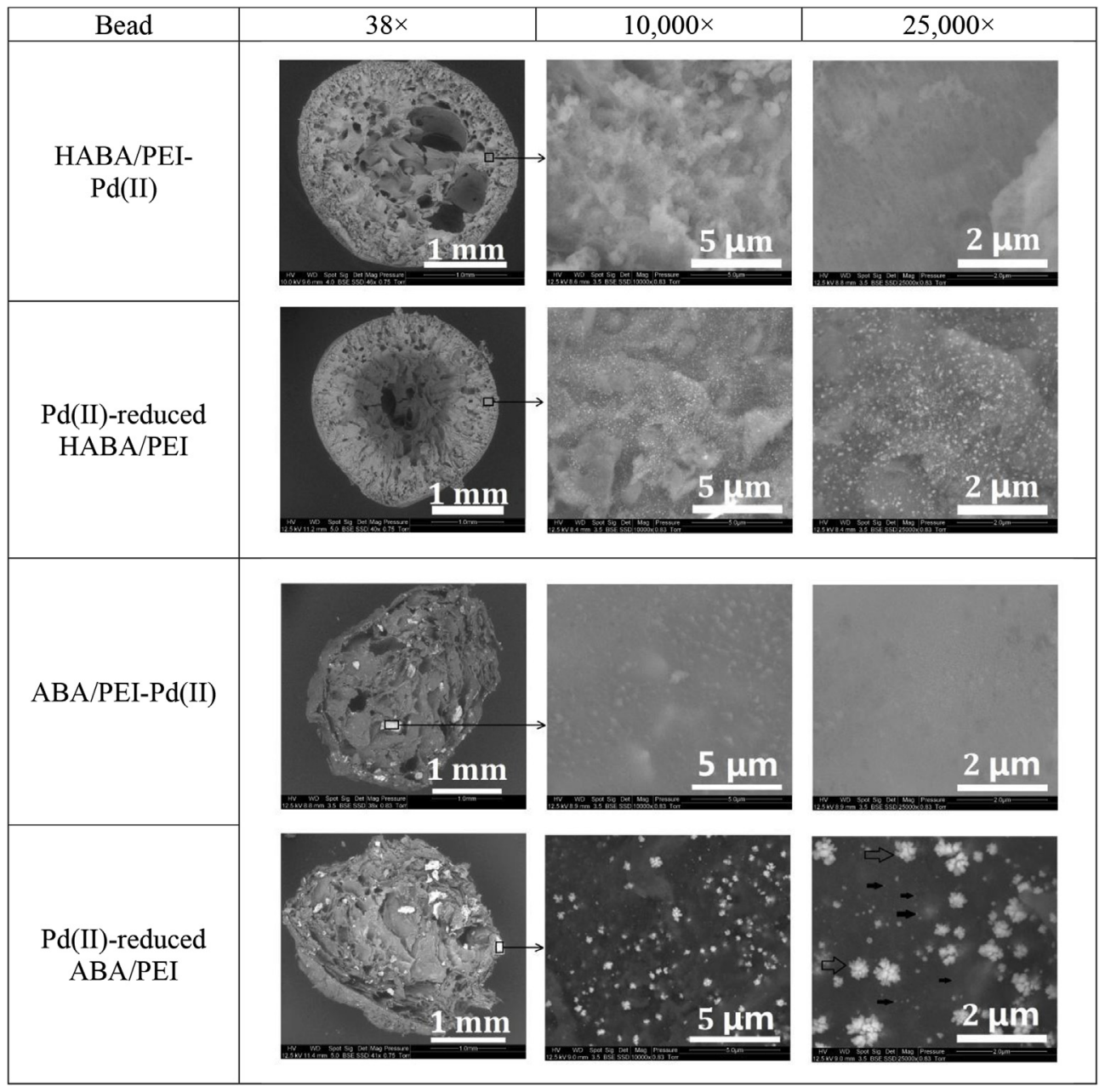

Fig. 2. SEM micrographs of Pd(II)-loaded and Pd-nanoparticles-loaded beads (Magnification: $38 \times, 10000 \times$ and $25000 \times$ ). 


\subsubsection{FTIR spectroscopy analysis}

The characteristic bands of the raw, Pd(II)-loaded and Pd(II)-desorbed beads were analyzed using FTIR-ATR. The spectra and the assignments of the main bands are presented in Fig. S6 and Table S1 (see Supplementary Material Section). The spectra for the two kinds of beads show generally similar features: both HABA/PEI and ABA/PEI beads have the same functional groups. The band observed at $3267 \mathrm{~cm}^{-1}$ for HABA/PEI and $3220 \mathrm{~cm}^{-1}$ for ABA/PEI corresponds to overlapping of $\mathrm{OH}$ and $\mathrm{NH}$ vibration modes [23]. The band at around $2928 \mathrm{~cm}^{-1}$ is assigned to $\mathrm{C}-\mathrm{H}$ stretching [24]. The peak at $1591 \mathrm{~cm}^{-1}$ corresponds to $\mathrm{C}=\mathrm{N}$ vibration, which is due to the reaction between primary amine groups of PEI and GA, forming "Schiff's base" [25]. The peak observed around $1429 \mathrm{~cm}^{-1}$ represents COO- symmetric stretching $[26,27]$. In a word, the main active functional groups on the beads that could be responsible for metal binding are carboxyl groups from alginate and amine groups from PEI-GA.

After $\mathrm{Pd}(\mathrm{II})$ sorption, the main change is the shift of $\mathrm{C}=\mathrm{N}$ vibration peak from $1591 \mathrm{~cm}^{-1}-1608 \mathrm{~cm}^{-1}$ for HABA/PEI, and to $1601 \mathrm{~cm}^{-1}$ for ABA/PEI beads. This confirms that Pd(II) sorption occurs on amine groups. Based on this, a new peak is appearing at $1729 \mathrm{~cm}^{-1}$ for both beads, assigned to the carboxylic acid $\mathrm{C}=\mathrm{O}$ stretching [28]; this could be explained by the fact that a part of carboxyl groups were converted to their anhydride form [28] or that the environment of carboxylic groups is affected by metal binding or by the acid solution $(\mathrm{pH} 1)$. Besides that, another peak corresponding to $\mathrm{CH}_{3}$ symmetric bending also appears.

For the Pd(II)-desorbed beads, the main change involves the shift of $\mathrm{C}=\mathrm{N}$ vibration peak from $1608 \mathrm{~cm}^{-1}-1619 \mathrm{~cm}^{-1}$ for HABA/PEI, and $1601 \mathrm{~cm}^{-1}$ to $1619 \mathrm{~cm}^{-1}$ for ABA/PEI. This change can be attributed to the utilization of $\mathrm{HCl}$ and thiourea solution as desorption agent, which could not only desorb Pd(II) but also chemically modify the sorbents. Indeed, many studies have used thiourea solution to increase the sorption capacity of the sorbents for precious metals such as Pt(IV), Pd (II) [29] or Au(III) [30]. Since desorption step may affect the chemical structure of the beads, further experiments (consecutive sorption-desorption cycles) will be carried out to verify if the sorption performance of the beads is significantly influenced by this possible change.

\subsection{Stability of the sorbents}

Experiments were conducted to investigate the stability of the beads over a period of $72 \mathrm{~h}$ in $\mathrm{NaCl}$ medium $(0.1-2 \mathrm{M})$ at $\mathrm{pH} 1$ and $\mathrm{pH} 5$. The materials were shaken with the solutions at $200 \mathrm{rpm}$. As shown in Fig. 3, HABA/PEI beads are sufficiently stable in the solutions at both $\mathrm{pH}$ values: the mass change rate increases as the concentration of $\mathrm{NaCl}$ increases, perhaps due to $\mathrm{NaCl}$ adsorption or absorption. The reason for this high stability should be that once PEI is homogeneously supported on HABA/PEI beads, the crosslinking reaction of GA and PEI, in turn, serves to strengthen the beads. PEI and GA are crosslinked before being incorporated into ABA/PEI beads, so these beads are unstable in $\mathrm{NaCl}$ solutions, especially at $\mathrm{pH} 5$ : when the $\mathrm{NaCl}$ concentration is more than $0.5 \mathrm{M}$, the beads are completely de-structured. The degradation is due to the ion exchange between $\mathrm{Na}(\mathrm{I})$ and $\mathrm{Ca}(\mathrm{II})$. The high shaking speed (200 rpm) may also contribute to this physical and chemical damages. Previously, Khoo and Ting [31] observed a significant mass loss (84\%) of alginate beads after stirring in deionized water at $500 \mathrm{rpm}$ for $70 \mathrm{~h}$. They also reported a low mechanical strength of alginate beads at low or high pH. Similarly, Stoichet et al. [32] found a weak stability of alginate beads when exposed to sodium salts $(50 \mathrm{mM})$. These results confirm the weak physical and chemical stability of raw alginate beads after shaking at a high speed or in a medium containing sodium salts; this is in agreement with the observation for ABA/PEI beads contrary to HABA/PEI beads; the post crosslinking reaction of homogeneously dispersed PEI with GA maintains the structure of the material. The inset photos graphically illustrate the effect of sodium salt $(1 \mathrm{M})$ on the stability of the beads: HABA/PEI beads are intact after the shaking process,
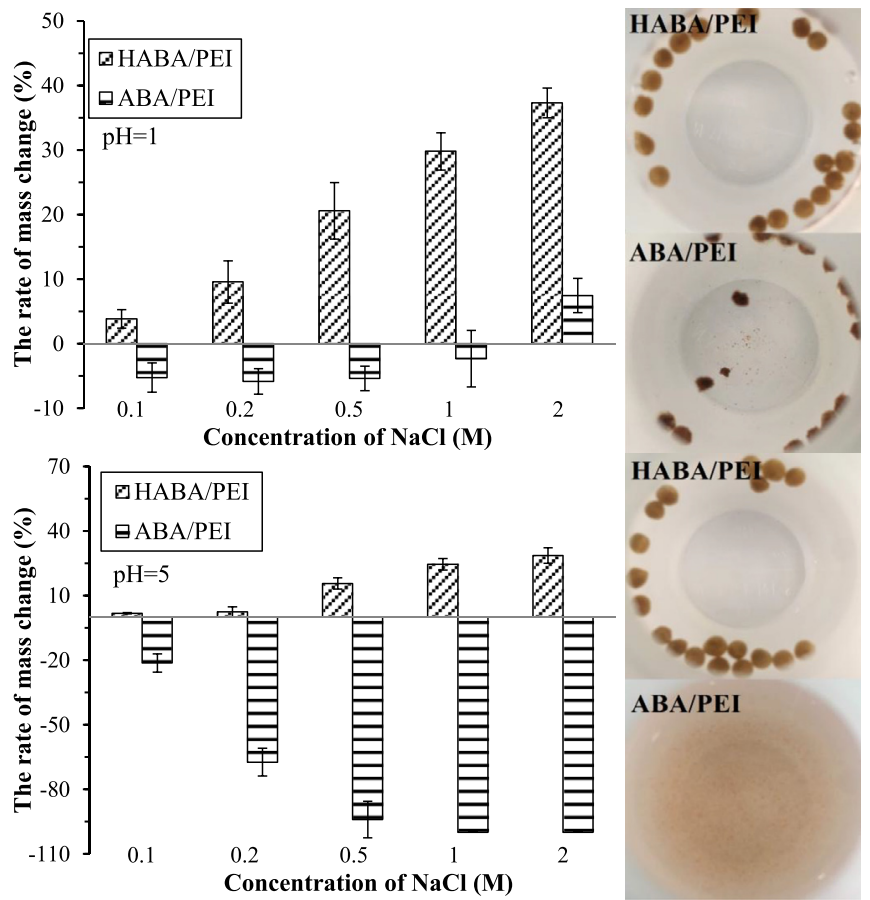

Fig. 3. Influence of $\mathrm{NaCl}$ at $\mathrm{pH} 1$ and $\mathrm{pH} 5$ on the stability of HABA/PEI and ABA/PEI beads; the inset photos show the beads after shaking with $2 \mathrm{M}$ of $\mathrm{NaCl}$ (V: $50 \mathrm{~mL}$; sorbent mass: $25 \mathrm{mg}$; time: $72 \mathrm{~h}$; shaking speed: $200 \mathrm{rpm}$; T: $20^{\circ} \mathrm{C}$ ).

while ABA/PEI beads are partially disintegrated at $\mathrm{pH} 1$ and almost totally degraded at $\mathrm{pH} 5$. This will undoubtedly affect their performance as sorbents or as supported catalysts, and/or their life cycle on operation.

\subsection{Palladium recovery}

\subsection{1. $p H$ effect}

To explore the potential for use in Pd(II) recovery, the beads were tested in batch experiments. The effect of $\mathrm{pH}$ on metal sorption is shown in Fig. 4(a). Obviously, Pd(II) binding onto the two types of beads is $\mathrm{pH}$ dependent. On PEI-modified algal/alginate beads, the main functional groups consist of carboxyl and amine groups. Pd(II) could bind to carboxyl groups by coordination and to protonated amine groups through electrostatic attraction/ion exchange (with anionic chlorocomplexes). When the sorption occurs through ligand exchange mechanisms, a low $\mathrm{pH}$ will lead to a decrease of sorption capacity due to the competition between the protonation and the Pd coordination [33], while in the case of electrostatic attraction, a low $\mathrm{pH}$ is usually required to positively charge the amine groups: protonated amine groups bind anionic complexes. It should be noted that, in this study, the concentration of $\mathrm{HCl}$ in the initial solutions diluted from stock solution was around $0.09 \mathrm{M}$, leading to predominant formation of chloro-palladium complexes $\left(\mathrm{PdCl}_{4}{ }^{2-}, 96 \%\right.$; $\mathrm{PdCl}_{3}{ }^{-}, 3-4 \%$ ) throughout the $\mathrm{pH}$ range. In this circumstance, $\mathrm{Pd}(\mathrm{II})$ binding onto the beads occurs mainly through electrostatic attraction (also confirmed by SEM-EDX). In the acidic aqueous media $\left(\mathrm{pH}_{\mathrm{eq}} 1-4\right)$, the sorption of chloro-anionic palladium increases with decreasing $\mathrm{pH}$ due to the protonation of the amine groups. The maximum sorption capacity is observed at $\mathrm{pH} 1$. However, when the $\mathrm{pH}$ continues decreasing (a greater amount of acid being added), the sorption capacity decreases gradually, probably due to the competition of sulfate anions. Many previous studies have confirmed that when the solution contains an excess of anions (e.g., $\mathrm{Cl}^{-}, \mathrm{SO}_{4}{ }^{2-}$, etc.), a competition may occur between those anions and chloro-metal anions for binding onto protonated amine groups [34,35]. The significant increase in $\mathrm{Pd}(\mathrm{II})$ binding when $\mathrm{pH}_{\mathrm{eq}}$ increases from 4 to 4.9 

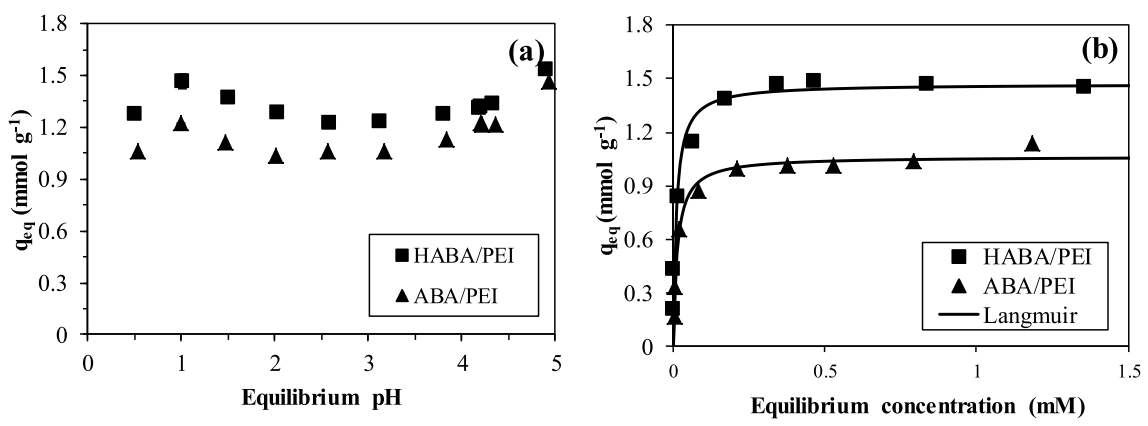

Fig. 4. (a) Influence of $\mathrm{pH}$ on $\mathrm{Pd}(\mathrm{II})$ sorption onto HABA/ PEI and ABA/PEI $\left(\mathrm{C}_{0}: 0.8 \mathrm{mmol} \mathrm{L}^{-1} ; \mathrm{pH}_{0}: 1-7\right.$; contact time: $72 \mathrm{~h}$; $\mathrm{T}$ : $20^{\circ} \mathrm{C}$; Dose: $0.25 \mathrm{~g} \mathrm{~L}^{-1}$; shaking speed: $150 \mathrm{rpm}$ ); (b) Pd(II) sorption isotherms using HABA/PEI and ABA/PEI beads (SD: $0.5 \mathrm{gL}^{-1} ; \mathrm{pH}$ : 1 , adjusted by $\mathrm{H}_{2} \mathrm{SO}_{4}$ or $\mathrm{NaOH}$; contact time: $72 \mathrm{~h}$; $\mathrm{T}: 20{ }^{\circ} \mathrm{C}$; shaking speed: $150 \mathrm{rpm}$ ). (corresponding to $\mathrm{pH}_{0}$ value of 4-7) could be attributed to the metal precipitation effect (the formation of low soluble Pd(II) species). Such trend has also been reported previously: for example, Pd(II) binding onto activated carbon was accompanied by microprecipitation when $\mathrm{pH}$ was higher than 3 (this limit of precipitation obviously depends on metal concentration) [2]. However, leaching liquors obtained from Pd (II) recovery process commonly contain a high concentration of acid (i.e., hydrochloric acid, sulfuric acid and/or nitric acid). Sorption process under a low $\mathrm{pH}$ can avoid the use of a massive amount of alkali chemicals for adjusting $\mathrm{pH}$. Therefore, further experiments were carried out at $\mathrm{pH} 1$.

\subsubsection{Sorption isotherms}

Fig. 4(b) shows the sorption isotherms of Pd(II) onto HABA/PEI and $\mathrm{ABA} / \mathrm{PEI}$ beads at $\mathrm{pH}$ 1. The incorporation of PEI-GA for Pd(II) binding has been previously studied: the immobilization of $9 \%(w / w)$ of PEI-GA can improve around 2.7 times sorption capacity at $\mathrm{pH} 2.5$ [15]. In this study, the amount of PEI and GA added was kept the same for both of the beads. However, as shown in Fig. 4(b), the maximum sorption capacity of HABA/PEI $\left(1.49 \pm 0.02 \mathrm{mmol} \mathrm{g}^{-1}\right)$ is significantly higher than that of ABA/PEI beads $\left(1.13 \pm 0.03 \mathrm{mmol} \mathrm{g}^{-1}\right)$. This is probably due to the uniform dispersion of PEI in HABA/PEI beads (as shown through SEM-EDX analysis), which makes amine groups more dispersed (i.e., increases the amine-Pd(II) contact area) and produces more accessible sorption sites for metal ions. The Langmuir and Freundlich models were used for fitting the experimental data. Parameters were evaluated by $\mathrm{R}^{2}$ (determination coefficient). The simulated plots and the corresponding parameters are shown in Fig. 3(b) (solid lines) and Table 1, respectively. The Langmuir model systematically show higher values of the determination coefficients compared to Freundlich model, regardless of the sorbents. The predicted values of $\mathrm{q}_{\mathrm{m}}$ by Langmuir model are $1.47 \mathrm{mmol} \mathrm{g}^{-1}$ for HABA/PEI and $1.06 \mathrm{mmol} \mathrm{g}^{-1}$ for ABA/ PEI beads, respectively, which are close to those obtained from experiments.

\subsubsection{Uptake kinetics}

In practice, a solid-liquid sorption process operated in either a batch or fixed-bed column system includes three steps: film diffusion (so-

Table 1

Sorption isotherms - Modeling parameters for Langmuir and Freundlich equations.

\begin{tabular}{llll}
\hline Model & Parameter & HABA/PEI & ABA/PEI \\
\hline \multirow{2}{*}{ Langmuir } & $\mathrm{q}_{\mathrm{eq}, \exp }\left(\mathrm{mmol} \mathrm{Pd} \mathrm{g}^{-1}\right)$ & 1.49 & 1.13 \\
& $\mathrm{q}_{\mathrm{eq}, \mathrm{cal}}\left(\mathrm{mmol} \mathrm{Pd} \mathrm{g}^{-1}\right)$ & 1.47 & 1.06 \\
& $\mathrm{~b}\left(\mathrm{~L} \mathrm{mmol}^{-1}\right)$ & 101.19 & 77.43 \\
& $\mathrm{R}^{2}$ & 0.90 & 0.98 \\
\hline \multirow{2}{*}{ Freundlich } & $\mathrm{K}_{\mathrm{F}}\left(\mathrm{mmol} \mathrm{g}^{-1}\right) /\left(\mathrm{mmol} \mathrm{L}^{-1}\right)^{\mathrm{n}}$ & 1.59 & 1.17 \\
& $\mathrm{n}$ & 6.56 & 5.24 \\
& $\mathrm{R}^{2}$ & 0.89 & 0.86 \\
\hline
\end{tabular}

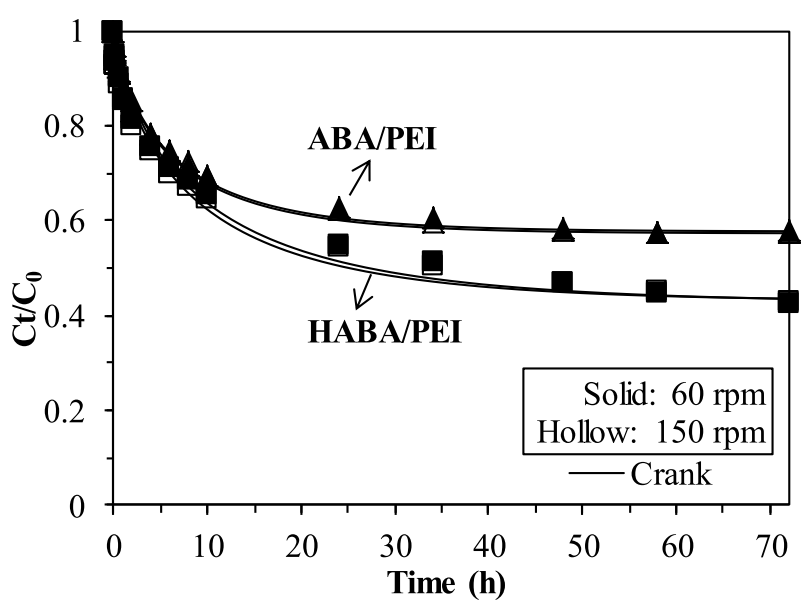

Fig. 5. Modeling of uptake kinetics with the Crank Equation for Pd(II) sorption using HABA/PEI and ABA/PEI beads at different agitating speeds $\left(\mathrm{C}_{0}\right.$ : $0.5 \mathrm{mmol} \mathrm{L}^{-1}$; V: $0.5 \mathrm{~L}$; sorbent mass: $100 \mathrm{mg}$; $\mathrm{pH}: 1$, adjusted by $\mathrm{H}_{2} \mathrm{SO}_{4}$ or $\mathrm{NaOH}$; contact time: $72 \mathrm{~h}$; T: $20^{\circ} \mathrm{C}$ ).

called external diffusion), intraparticle diffusion and surface reaction. Providing a sufficient agitation speed to the batch reactor helps in reducing the influence of resistance to film diffusion. Fig. 5 shows that the plots obtained at two agitation speeds (i.e., 60 and $150 \mathrm{rpm}$ ) are almost overlapped (even within the first few hours), indicating that film diffusion should not be the rate controlling step for uptake kinetics [36,37]. In addition, Pd(II) sorption onto HABA/PEI is slower than ABA/PEI beads. The plots of $\mathrm{q}_{\mathrm{t}} / \mathrm{q}_{\mathrm{eq}}$ vs. $\mathrm{t}$ (Fig S6, see Supplementary Material Section) illustrate this phenomenon more clearly: at $4 \mathrm{~h}, \mathrm{ABA} /$ PEI beads reach $52 \%$ of equilibrium sorption capacity, while the value for HABA/PEI is $43 \%$ and to achieve more than $98 \%$ of $q_{\text {eq }}$, it requires $48 \mathrm{~h}$ for ABA/PEI, and more than $58 \mathrm{~h}$ for HABA/PEI beads. The difference in equilibrium time for these two kinds of beads could be attributed to the tighter structure of HABA/PEI beads, which has been observed and discussed in the section relative to SEM-EDX analysis. Several models including the pseudo-second order rate equation (PSORE), the pseudo-first order rate equation (PFORE) and Crank equation were used to fit the experimental data. The fitting plots (Fig. S8, see Supplementary Material Section) indicate that PFORE and PSORE fail to model the experimental data: great discrepancies are observed between the experimental values of $\mathrm{C}_{t} / \mathrm{C}_{0}$ and the corresponding calculated values. On the opposite hand, the Crank equation is much more efficient for predicting the experimental profiles (Fig. 5). Based on the assumption of this model, the external diffusion and surface reaction should be more rapid than intraparticle diffusion for Pd (II) sorption onto the beads. The intraparticle diffusion coefficients $\left(D_{\mathrm{e}}\right)$ for the beads are reported in Table 2: the $D_{\mathrm{e}}$ value of ABA/PEI (at $60 \mathrm{rpm}$ for example) is $9.84 \times 10^{-10} \mathrm{~m}^{2} \mathrm{~min}^{-1}$, higher than that of HABA/PEI beads $\left(5.25 \times 10^{-10} \mathrm{~m}^{2} \mathrm{~min}^{-1}\right)$, but two orders of magnitude lower than the self-diffusivity of $\mathrm{PdCl}_{4}{ }^{2-}\left(8.34 \times 10^{-8} \mathrm{~m}^{2} \mathrm{~min}^{-1}\right)$ in water [38]. This confirms that the resistance to intraparticle diffusion 
Table 2

Modeling of sorption kinetics of Pd(II) onto HABA/PEI and ABA/PEI (Crank equation).

\begin{tabular}{llll}
\hline Sorbent & Agitation speed (rpm) & $\mathrm{D}_{\mathrm{e}} \times 10^{-10}\left(\mathrm{~m}^{2} \mathrm{~min}^{-1}\right)$ & SSR \\
\hline HABA/PEI & 60 & 5.25 & 0.0561 \\
& 150 & 5.83 & 0.064 \\
ABA/PEI & 60 & 9.84 & 0.0362 \\
& 150 & 9.91 & 0.0514 \\
\hline
\end{tabular}

plays a significant role in the control of uptake kinetics. The results are also in agreement with the observation from SEM-EDX analysis (element maps of Pd at different time intervals, Fig. 1).

\subsubsection{Reuse of the sorbent}

The competitiveness of a sorption process is controlled by the recovery of the target metal and/or the possibility to recycle the sorbent. The reusability of the beads for Pd(II) recovery was tested through successive sorption-desorption cycles. The mass of the beads during each cycle was measured. Many previous studies have shown that acidic thiourea solution can efficiently desorb Pd(II) from amine groupbased sorbents [39,40]. Therefore, $0.1 \mathrm{M} \mathrm{HCl} / 0.2 \mathrm{M}$ thiourea solution was used as the desorption agent. Results presented in Fig. 6 show the changes in the (a) sorption efficiency, (b) desorption efficiency, (c) mass change rate and (d) concentration factor (CF) during 5 sorptiondesorption cycles. The sorption efficiency in the first cycle is $84.1 \%$ for HABA/PEI and $70.2 \%$ for ABA/PEI beads, while the desorption efficiency are $64.7 \%$ and $81.4 \%$, respectively. Since the desorption efficiency is lower than $100 \%$, a fraction of the sorbed Pd(II) remains on the beads after each cycle, which is expected to reduce the sorption capacity of the sorbents. Interestingly, the sorption capacity is, however, significantly improved after the first cycle. Such an improvement on sorption capacity after desorption process using acidic thiourea has been previously reported [5]. As mentioned above in FTIR-ATR analysis, the beads are chemically modified after desorption process. Indeed, after the sorption process in the second cycle, the color of the beads turns into brown (see photo in Fig. S9a, Supplementary Material Section). This phenomenon becomes more significant after 5 cycles: the color of the beads is totally black (Fig. S9b), which indicates the formation of PdS or reduction of Pd(II) happening along with sorption after the contact with acidic thiourea. However, this conclusion requires further verification. As the cycles continue, whereas HABA/PEI beads maintain the sorption efficiency around 98\%, ABA/PEI beads present a decreasing trend in $\mathrm{Pd}(\mathrm{II})$ sorption. This can be explained by the mass change rate of the beads measured during each cycle. The mass of HABA/PEI beads slightly increases along the cycles, perhaps due to the loading of Pd(II) or modification by acidic thiourea, while that of ABA/PEI beads decreases dramatically. This result also confirms much higher stability of HABA/PEI compared to ABA/PEI beads when reused for several times. The concentration factor (CF) was calculated as $\mathrm{Pd}(\mathrm{II})$ concentration in the desorption agent divided by its value in the initial solution. During the sorption/desorption cycles, $\mathrm{CF}$ is found to be 7.5-11.0 and 10.2-12.4 for HABA/PEI and ABA/PEI beads, respectively. To conclude, although it is easier to desorb Pd(II) for ABA/ PEI beads than for HABA/PEI beads (shown by a higher CF of ABA/PEI beads), the much higher stability of HABA/PEI beads makes them more practically applicable.

\subsection{Nitrophenol reduction}

\subsubsection{Selection of $P d(I I)$ reduction procedure}

In order to evaluate the application potential of the beads as supported catalysts, the Pd(II)-loaded beads were submitted to a Pd(II)reduction process before being used for 3-nitrophenol (3-NP) reduction (using sodium formate as hydrogen donor). Different reagents, including ethanol, hydrazine, and in situ generated hydrogen (by the reaction of zinc powder and sulfuric acid) were firstly used to verify the Pd(II) reduction procedure: the catalytic activity of the corresponding catalysts was compared. Control experiments were also performed in the absence of the catalysts but with the presence of the raw beads (HABA/PEI and ABA/PEI beads) and Pd(II)-loaded beads. The residual 3-NP concentration decreases by around $4 \mathrm{mg} \mathrm{L}^{-1}$ after 7 -h reaction when using raw beads (shown in Fig. 7(a)), probably due to sorption behavior, demonstrating the limited contribution of sorption for 3-NP reduction. Since Pd(II) can be gradually reduced by sodium formate, the concentration of 3-NP is only reduced by $10.2 \mathrm{mg} \mathrm{L}^{-1}$ when using Pd(II)-loaded HABA/PEI, while in the case of ABA/PEI-Pd(II), it decreases by more than $25 \mathrm{mg} \mathrm{L}^{-1}$. This phenomenon indicates that a prereduction treatment is highly required for Pd(II)-loaded HABA/PEI beads. Although all pre-reduced catalysts show enhanced activity, the reduction with ethanol reflux is not sufficient: the reduction efficiency of 3-NP using ethanol-treated catalysts is almost the same compared to
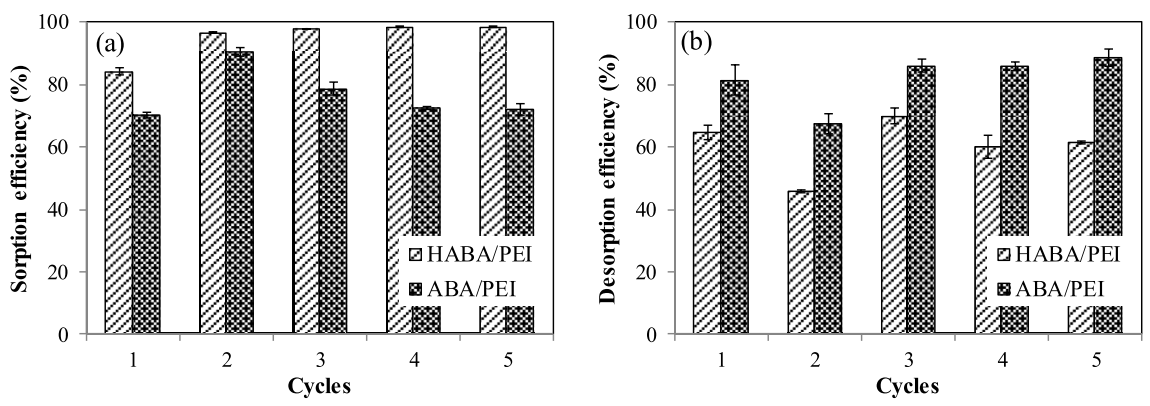

Fig. 6. Reuse of HABA/PEI and ABA/PEI beads for Pd(II) sorption: (a) sorption efficiency; (b) desorption efficiency; (c) mass change rate and (d) concentration factor (Sorption step: $\mathrm{pH} \mathrm{1;} \mathrm{C}_{0}, 0.25 \mathrm{mmol} \mathrm{L}^{-1}$; V, $100 \mathrm{~mL}$; sorbent mass, $20 \mathrm{mg}$; $\mathrm{T}, 20^{\circ} \mathrm{C}$; shaking speed, $150 \mathrm{rpm}$; contact time, $48 \mathrm{~h}$ - Desorption step: desorption agent, $0.1 \mathrm{M} \mathrm{HCl} / 0.2 \mathrm{M}$ thiourea; V, $5 \mathrm{~mL}$; T, $50^{\circ} \mathrm{C}$; time, $24 \mathrm{~h}-$ Washing step: V, $5 \mathrm{~mL} ; \mathrm{T}, 50^{\circ} \mathrm{C}$; time, $24 \mathrm{~h}$ ).
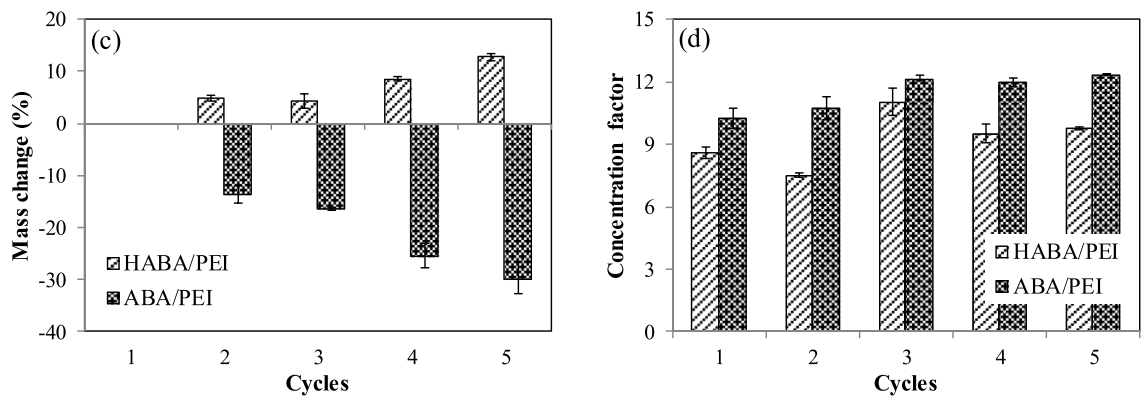

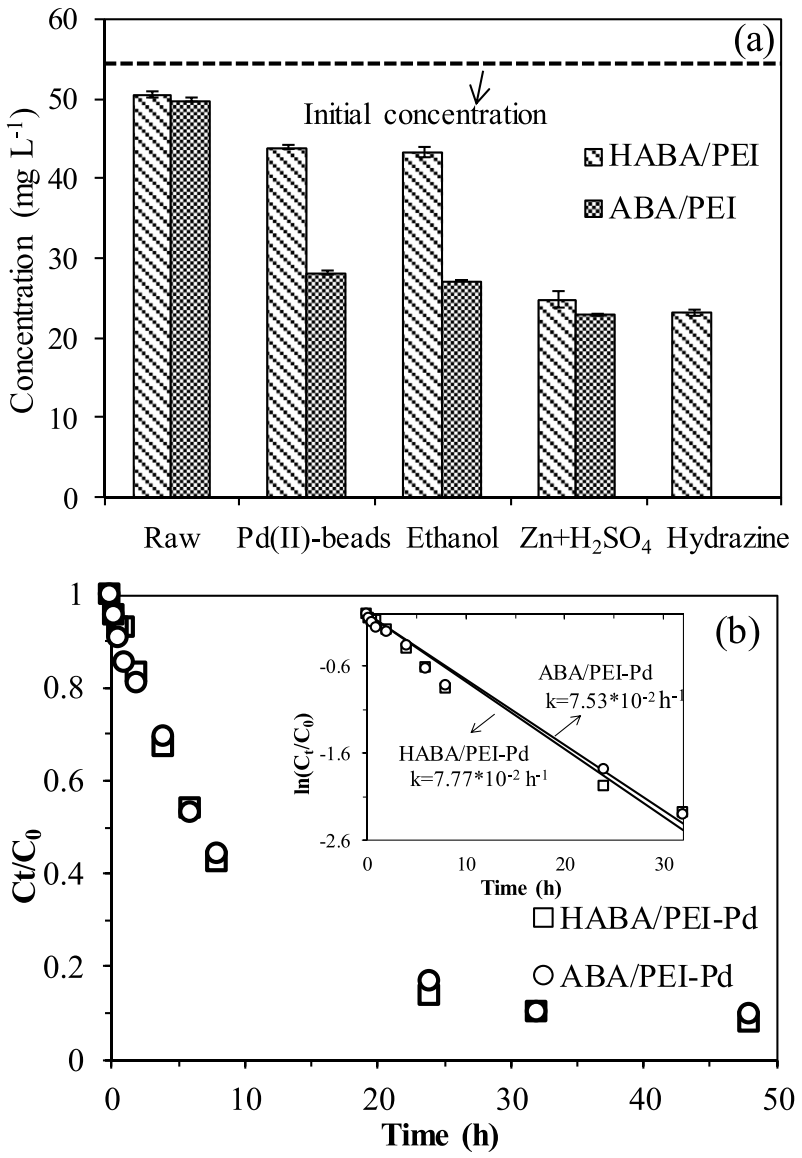

Fig. 7. (a) Effect of catalyst synthesis procedure for 3-NP reduction (catalyst mass: $10 \mathrm{mg}$; Pd loaded amount: $102 \mathrm{mg} \mathrm{g}^{-1}$ for HABA/PEI and $118 \mathrm{mg} \mathrm{g}^{-1}$ for $\mathrm{ABA} / \mathrm{PEI}$; Volume: $50 \mathrm{~mL}$; $\mathrm{C}_{0}$ of 3-NP: $50 \mathrm{mg} \mathrm{L}^{-1}$; $\mathrm{pH}$ : 3; sodium formate concentration: $25 \mathrm{mM}$; contact time: $6 \mathrm{~h}$; T: $20^{\circ} \mathrm{C}$; shaking speed: $150 \mathrm{rpm}$ ); (b) Kinetics of reduction reaction of 3-NP (catalyst mass: $40 \mathrm{mg}$; Pd loaded amount: $102 \mathrm{mg} \mathrm{g}^{-1}$ for HABA/PEI and $118 \mathrm{mg} \mathrm{g}^{-1}$ for ABA/PEI; Volume: $200 \mathrm{~mL}$; $\mathrm{C}_{0}$ of 3-NP: $50 \mathrm{mg} \mathrm{L}^{-1}$; $\mathrm{pH}$ : 3; sodium formate concentration: $25 \mathrm{mM}$; T: $20^{\circ} \mathrm{C}$; shaking speed: $150 \mathrm{rpm})$. Inset Image: Plots of $\ln \left(\mathrm{C}_{\mathrm{t}} / \mathrm{C}_{0}\right) v s$. time for the reduction of 3-NP.

those using Pd(II)-loaded beads. For HABA/PEI, hydrazine reduction produces a little more efficient catalysts than the in situ generated hydrogen. However, in the case of ABA/PEI beads, the beads were degraded in hydrazine solution after heating up to $60^{\circ} \mathrm{C}$, while the generated hydrogen enables them to present a comparable performance compared to hydrazine-treated HABA/PEI. Therefore, for further experiments, hydrazine will be used for producing HABA/PEI supported catalyst, while in the case of ABA/PEI catalyst, zinc powder and $\mathrm{H}_{2} \mathrm{SO}_{4}$ will be used for in situ generated production and metal reduction.

\subsubsection{Reduction kinetics}

Fig. 7(b) illustrates the reduction reaction of 3-NP observed at different time intervals using the catalysts prepared by the above methods. To determine the catalytic activity of the catalysts, the pseudo-firstorder kinetics was applied. The equation can be described as $\ln \left(\mathrm{C}_{\mathrm{t}} /\right.$ $\left.\mathrm{C}_{0}\right)=-\mathrm{kt}$, where $\mathrm{k}$ is the apparent first-order rate constant $\left(\mathrm{h}^{-1}\right)$, and $t$ is the reaction time $(h)$. As shown in inset figure, the plots $\ln \left(\mathrm{C}_{t} / \mathrm{C}_{0}\right) v s$. t present a straight line, suggesting that this equation fits well the kinetic profiles. As observed in SEM micrographs (section 3.1), some aggregates of Pd nanoparticles are found on ABA/PEI-Pd. It is expected that HABA/PEI-Pd shows better catalytic performance compared to ABA/PEI-Pd. However, the rate constant $(\mathrm{k})$ calculated is $7.77 \times 10^{-2} \mathrm{~h}^{-1}$ (i.e., $2.16 \times 10^{-5} \mathrm{~s}^{-1}$ ) for the reaction catalyzed using HABA catalyst, very close to $7.53 \times 10^{-2} \mathrm{~h}^{-1}$ (i.e.,
$2.09 \times 10^{-5} \mathrm{~s}^{-1}$ ) for that using ABA catalyst. This could be due to a slightly higher amount of Pd on ABA catalyst (because of different initial metal concentrations in sorption process) and a higher fraction of reduced Pd (at least at the surface of the beads, see below Section 3.4.3.); indeed, the catalytic activity $\left(\mathrm{k}_{\mathrm{Pd}}=\mathrm{k} / \mathrm{m}\right)$, which is the ratio of the rate constant $v s$. the total amount of Pd loaded on the beads, calculated for HABA catalyst is $0.53 \times 10^{-2} \mathrm{~s}^{-1} \mathrm{~g}^{-1}$, higher than $0.44 \times 10^{-2} \mathrm{~s}^{-1} \mathrm{~g}^{-1}$ for ABA catalyst. Moreover, another reason could be the greater intraparticle diffusion resistance inside HABA/PEI compared to ABA/PEI beads (discussed above in sorption kinetics). The photos of the catalysts after 3-NP reduction show that HABA/PEI-Pd beads are much more stable than ABA/PEI-Pd (Fig. S10, see Supplementary Material Section). The observation suggests a better application potential of HABA/PEI-Pd. However, HABA/PEI-Pd does not show competitive catalytic performance when compared to other catalysts reported previously. Gu et al. [41] found a rate constant of $10.5 \times 10^{-3} \mathrm{~s}^{-1}$ for Pd nanoparticles supported on carbon nanotube. Similarly, Li and co-workers [42] used carbon nanotubes for supporting Pd nanoparticles: they obtained a good catalytic performance toward the reduction of 4-nitrophenol with a rate constant of $5 \times 10^{-3} \mathrm{~s}^{-1}$ $\left(0.3 \mathrm{~min}^{-1}\right)$. Srinivasan et al. [43] reported a rate constant of $6.58 \times 10^{-2} \mathrm{~s}^{-1}$ for palladium (Pd) nanoparticles incorporated poly$(3,4)$ ethylenedioxythiophene. Highly dispersed Pd/polypyrrole nanocapsules reported by Xue and co-workers [44] have a reaction rate constant of $8.87 \times 10^{-3} \mathrm{~s}^{-1}$ for 4-nitrophenol, while in the case of Pd supported on nano-silica the rate constant was close to $5.5 \times 10^{-4} \mathrm{~s}^{-1}$ [45]. HABA/PEI-Pd presents a lower value of rate constant than all these nanostructured catalysts mentioned above, probably due to intraparticle transport limitations (as shown in sorption kinetics). However, it is not entirely appropriate to evaluate the catalytic performance by comparing only the rate constant, since lots of factors should be taken into consideration for the practical application, such as the mass of Pd nanoparticles applied, the size of the support, the kind of agent used as hydrogen donor, the volume and concentration of 3-NP, etc. Moreover, the stability, separability and reusability are also of great importance. A larger size of support is supposed to lead to a lower rate constant [41] but facilitates the catalyst recovery step. Therefore, the main interest of the catalysts prepared in this study is based on the fact that the support is green, readily available, low cost, easily separable from solution (large size of the supports: around $0.3 \mathrm{~cm}$ ) and very versatile physically. Ongoing research is investigating the use of the same material conditioned as scaffolds (highly porous foams) with very thin walls that minimize intraparticle diffusion.

\subsubsection{Reuse of the catalysts}

The solid-liquid separation is of great importance for reuse purpose of the catalysts. It is generally performed by either centrifugation or magnetic separation, when relevant, using an external magnetic field, which could lead to catalyst loss. In this study, because of a large size (around $0.3 \mathrm{~cm}$ ) of the supports, the catalysts can be recovered simply by sieving (size: $2 \mathrm{~mm}$ ).

To clarify the reusability of the catalysts, the catalysts were applied for 3-NP reduction for four consecutive cycles. After the completion of reaction, the catalysts were washed with water several times and employed for the next cycle. The plots of $\mathrm{C}_{\mathrm{t}} / \mathrm{C}_{0} v s \mathrm{t}$ for 3-NP catalyzed by HABA/PEI-Pd beads in different cycles are almost overlapped, indicating they can be recycled, while in the case of ABA/PEI-Pd beads, a little decrease is observed in terms of reduction rate (Fig. 8), which could be due to the relatively weaker stability (shown in Fig. S9, see Supplementary Material Section).

\subsubsection{XPS analysis of catalysts}

The Pd(II)-loaded sorbents were analyzed by XPS and compared with the catalysts (i.e., after metal reduction) but also with the catalyst after being re-used. The XPS surveys of the materials are reported in Fig. S11 (see Supplementary Material Section). Tables 3 and 4 report 

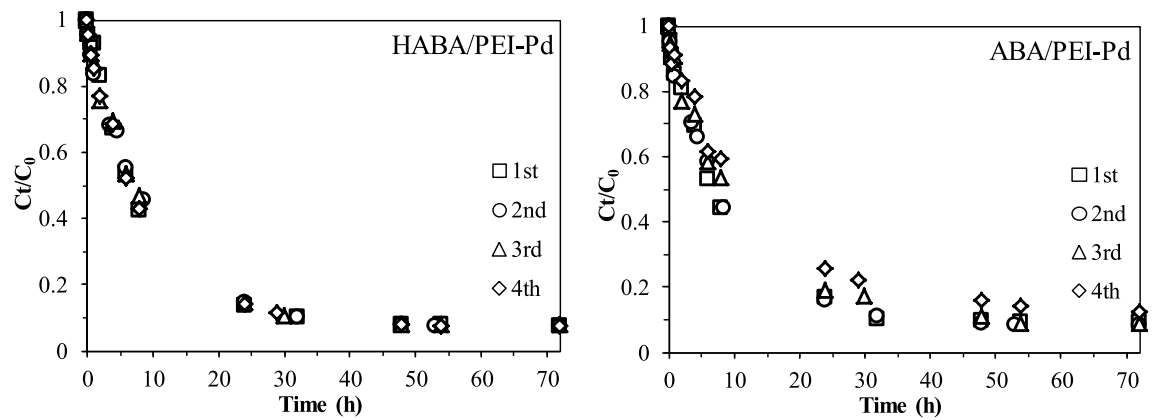

Fig. 8. Reuse of HABA/PEI-Pd and ABA/PEI-Pd catalysts for 3-NP reduction (catalyst mass: $40 \mathrm{mg}$; Pd loaded amount: $102 \mathrm{mg} \mathrm{g}^{-1}$ for $\mathrm{HABA}^{\mathrm{PEI}}$ and $118 \mathrm{mg} \mathrm{g}^{-1}$ for ABA/PEI; Volume: $200 \mathrm{~mL}$; $\mathrm{C}_{0}$ of 3-NP: $50 \mathrm{mg} \mathrm{L}^{-1}$; $\mathrm{pH}$ : 3; $\mathrm{T}: 20^{\circ} \mathrm{C}$; shaking speed: $150 \mathrm{rpm}$ ).

the assignments of different XPS bands for the most representative elements (i.e., $\mathrm{C}, \mathrm{N}, \mathrm{O}$ and $\mathrm{Pd}$ ) and the fractional contributions of the different chemical groups associated to these elements for HABA and ABA based-materials respectively; while Table 5 proposes the identification of the different relevant binding energies (BEs). Survey scans show that several other elements with low concentration have been also detected; for example $\mathrm{Si}, \mathrm{Na}$, and especially $\mathrm{Cl}$ element (associated with palladium binding, as chloro-complexes) was observed. The presence of $\mathrm{Zn}$ elements identified on ABA/PEI-Pd beads after reduction is coherent with the mode of reduction selected for this material: indeed, Pd(II) was reduced on ABA/PEI sorbent by $\mathrm{H}_{2}$ release from the reaction of sulfuric acid on zinc powder. On the opposite hand, the presence of $\mathrm{Na}$ on HABA/PEI beads can be explained by the use of $\mathrm{NaOH}$ and hydrazine hydrate for metal reduction.

Figs. S12-S17 report the multi-region spectra of C 1s, N 1s, O 1s, Pd $3 \mathrm{~d}$ and $\mathrm{S} 2 p$ for the different materials, including raw spectra, de-convoluted peaks and composite signals. Tables S2 and S3 (see Supplementary Material Section) report the complete sets of typical element bands. XPS analysis is a surface analysis; the homogeneity of HABAbased materials compared to ABA-based supports may explain the relatively higher content of $\mathrm{Pd}$ in the materials compared to ABA. Pd is bound to amine groups of PEI dispersed in the whole mass of the material while for ABA-based materials PEI is heterogeneously incorporated as larger particles: the atomic percentages are less reproducible for ABA-based materials and the relative fraction of PEI and Pd at the surface is lower than the expected theoretical contents based on sorption capacities.

For N $1 s$ signal, two contributions can be systematically detected that represent alkyl amino groups (in the range 399.4-400.0 eV) and their protonated form (alkyl-ammonium groups in the range 401.1-402.2 eV) [46]: it is not possible establishing a rationale for the little changes in their relative fractions with the type of sorbent and the treatment of the sample (reduction, re-use); anyway, free amino groups are systematically predominating against protonated forms (61.5-89.1\% vs. $10.9-38.47 \%$ ). More interesting is the discussion of $O$ 1s signal. Indeed, substantial differences are observed between HABA and $\mathrm{ABA}$ materials when the material is submitted to the reduction process. While for HABA-based catalyst a substantial part (about $23-28 \%$ ) of $\mathrm{O}$ element is under the form of carboxylate groups (at around 530-531 eV) [47-49], for ABA-based material the reduction did not change the chemical state of $\mathrm{O}$ element (completely present as $\mathrm{C}-\mathrm{OH}$ group). The partial conversion into carboxylate groups is only observed on the re-used catalyst (to a lesser extent than for HABA material; i.e., 14.1\%). However, this discussion should be carefully considered since carboxylate groups are supposed to be uniformly present in all materials due to the use of alginate as the encapsulating material. This is confirmed by the systematic presence of a contribution at $288-289 \mathrm{eV}$ for C 1 s core level signal, which is representative of C element in the environment of carboxylate groups [47,48,50] (about $3-10 \%$ of total C element). The contribution at around $287.2-287.8 \mathrm{eV}$ represents $\mathrm{C}=\mathrm{O}$ functions: this band is present in all the samples though more important on ABA-based material (with a fraction ranging between $11.7 \%$ and $15.1 \%$ against less than $7.51-11.44 \%$ for HABAbased material); this is probably explained by a weaker interaction between carboxylic groups of alginate and amine groups of PEI. The third contribution corresponding to the $\mathrm{C}$ 1s signal (in the range

Table 3

XPS analyses of Samples: A (HABA/PEI-Pd), B (HABA/PEI-Pd after Pd reduction: catalyst) and C (HABA/PEI-Pd catalyst re-used) - Surface atomic fraction of main elements and relative contributions of their different forms (speciation, environment, etc.).

\begin{tabular}{|c|c|c|c|c|c|c|c|c|}
\hline Sample & C $1 \mathrm{~s}$ & & O 1s & & $\mathrm{N} 1 \mathrm{~s}$ & & $\operatorname{Pd} 3 d_{5 / 2}$ & \\
\hline \multirow[t]{5}{*}{ A } & $284.7 \mathrm{eV}$ & 52.03 & $532.4 \mathrm{eV}$ & 92.33 & $399.9 \mathrm{eV}$ & 71.14 & $336.1 \mathrm{eV}$ & 23.96 \\
\hline & $286.0 \mathrm{eV}$ & 35.07 & $535.1 \mathrm{eV}$ & 7.67 & $401.8 \mathrm{eV}$ & 28.86 & $337.6 \mathrm{eV}$ & 76.04 \\
\hline & $287.3 \mathrm{eV}$ & 7.79 & & & & & & \\
\hline & $288.6 \mathrm{eV}$ & 5.11 & & & & & & \\
\hline & 63.53 & & 25.93 & & 5.78 & & 2.14 & \\
\hline \multirow[t]{5}{*}{ B } & $284.6 \mathrm{eV}$ & 47.65 & $530.9 \mathrm{eV}$ & 27.53 & $399.4 \mathrm{eV}$ & 89.10 & $334.9 \mathrm{eV}$ & 50.42 \\
\hline & $285.9 \mathrm{eV}$ & 39.79 & $532.4 \mathrm{eV}$ & 69.37 & $401.3 \mathrm{eV}$ & 10.90 & $336.4 \mathrm{eV}$ & 21.76 \\
\hline & $287.2 \mathrm{eV}$ & 7.51 & $534.9 \mathrm{eV}$ & 3.09 & & & $337.9 \mathrm{eV}$ & 27.82 \\
\hline & $288.0 \mathrm{eV}$ & 5.05 & & & & & & \\
\hline & 64.10 & & 26.46 & & 6.45 & & 1.86 & \\
\hline \multirow[t]{5}{*}{$\mathrm{C}$} & $284.4 \mathrm{eV}$ & 44.15 & $530.7 \mathrm{eV}$ & 22.85 & $399.4 \mathrm{eV}$ & 79.22 & $335.0 \mathrm{eV}$ & 42.72 \\
\hline & $285.8 \mathrm{eV}$ & 41.64 & $532.4 \mathrm{eV}$ & 72.60 & $401.1 \mathrm{eV}$ & 20.78 & $336.4 \mathrm{eV}$ & 15.35 \\
\hline & $287.2 \mathrm{eV}$ & 11.44 & $534.9 \mathrm{eV}$ & 4.55 & & & $337.9 \mathrm{eV}$ & 41.93 \\
\hline & $288.4 \mathrm{eV}$ & 2.77 & & & & & & \\
\hline & 49.26 & & 40.65 & & 6.40 & & 1.00 & \\
\hline
\end{tabular}


Table 4

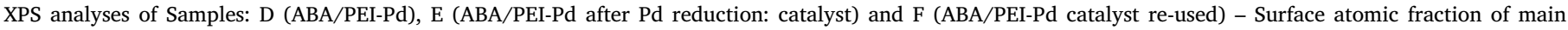
elements and relative contributions of their different forms (speciation, environment, etc.).

\begin{tabular}{|c|c|c|c|c|c|c|c|c|}
\hline Sample & C $1 \mathrm{~s}$ & & $\mathrm{O} 1 \mathrm{~s}$ & & $\mathrm{~N} 1 \mathrm{~s}$ & & $\operatorname{Pd} 3 d_{5 / 2}$ & \\
\hline \multirow[t]{5}{*}{$\mathrm{D}$} & $284.7 \mathrm{eV}$ & 33.24 & $532.5 \mathrm{eV}$ & 100.00 & $400.0 \mathrm{eV}$ & 61.53 & $336.0 \mathrm{eV}$ & 71.21 \\
\hline & $286.2 \mathrm{eV}$ & 41.64 & & & $401.9 \mathrm{eV}$ & 38.47 & $337.6 \mathrm{eV}$ & 28.79 \\
\hline & $287.6 \mathrm{eV}$ & 15.08 & & & & & & \\
\hline & $288.9 \mathrm{eV}$ & 10.04 & & & & & & \\
\hline & \multicolumn{2}{|l|}{58.46} & \multicolumn{2}{|l|}{37.89} & \multicolumn{2}{|l|}{1.91} & \multicolumn{2}{|l|}{0.39} \\
\hline \multirow[t]{5}{*}{$\mathrm{E}$} & $284.8 \mathrm{eV}$ & 45.37 & $532.6 \mathrm{eV}$ & 100.00 & $399.9 \mathrm{eV}$ & 62.03 & $335.6 \mathrm{eV}$ & 71.34 \\
\hline & $286.4 \mathrm{eV}$ & 34.07 & & & $401.9 \mathrm{eV}$ & 37.97 & $337.32 \mathrm{eV}$ & 28.66 \\
\hline & $287.7 \mathrm{eV}$ & 11.74 & & & & & & \\
\hline & $289.0 \mathrm{eV}$ & 8.82 & & & & & & \\
\hline & \multicolumn{2}{|l|}{56.10} & \multicolumn{2}{|l|}{40.21} & \multicolumn{2}{|l|}{1.07} & \multicolumn{2}{|l|}{0.14} \\
\hline \multirow[t]{5}{*}{$\mathrm{F}$} & $284.8 \mathrm{eV}$ & 39.76 & $531.2 \mathrm{eV}$ & 14.08 & $399.8 \mathrm{eV}$ & 82.01 & $335.4 \mathrm{eV}$ & 44.78 \\
\hline & $286.3 \mathrm{eV}$ & 38.31 & $532.7 \mathrm{eV}$ & 83.27 & $402.2 \mathrm{eV}$ & 17.99 & $336.6 \mathrm{eV}$ & 30.77 \\
\hline & $287.8 \mathrm{eV}$ & 15.06 & $535.3 \mathrm{eV}$ & 2.65 & & & $338.2 \mathrm{eV}$ & 24.45 \\
\hline & $288.9 \mathrm{eV}$ & 6.87 & & & & & & \\
\hline & 61.30 & & 37.05 & & 1.07 & & 0.03 & \\
\hline
\end{tabular}

Table 5

Assignment of main signals.

\begin{tabular}{lll}
\hline & Binding Energy (eV) & Assignment \\
\hline C 1s & $284.4-284.6-284.7$ & C, alkyl (C-C), aromatic (C=C) \\
& $285.8-285.9-286.0-286.2-286.3-$ & C-N, C-OH, C-O-C \\
& 286.4 & \\
& $287.2-287.3-287.6-287.8$ & $\mathrm{C}=\mathrm{O}$ \\
& $288.0-288.4-288.6-288.9-289.0$ & Carboxylate \\
\cline { 2 - 3 } O 1s & $530.7-530.9-531.2$ & Carboxylate $(\mathrm{C}=\mathrm{O})$ \\
& $532.4-532.5-532.6-532.7$ & $\mathrm{C}-\mathrm{OH}$, oxides \\
& $534.9-535.1-535.3$ & $\mathrm{H}_{2} \mathrm{O}$ \\
\cline { 2 - 3 } $\mathrm{N} 1 s$ & $399.4-399.8-399.9-400.0$ & Alkyl-amino \\
& $401.1-401.3-401.8-401.9-402.2$ & Alkyl-ammonium \\
\cline { 2 - 3 } Pd 3d & $334.9-335.0$ & Pd(0) \\
& $336.1-336.4$ & Pd(II) as sulfide \\
& $337.6-337.9$ & Pd(II) as sulfate \\
\cline { 2 - 3 } S 2p & $161.5-162.0-162.1-162.6$ & Sulfide \\
& $167.5-167.7-168.4-168.5-169.0-$ & Sulfate \\
& 170.2 & \\
\hline
\end{tabular}

$285.8-286.4 \mathrm{eV}$ ) is attributed to bonds between $\mathrm{C}$ and $\mathrm{N}, \mathrm{OH}$ or $\mathrm{C}-\mathrm{O}-\mathrm{C}$ : its relative contribution ranges between $35 \%$ and $42 \%$ for HABA-based material and between $34 \%$ and $42 \%$ for ABA-based material (without any clear trend in function of the treatment applied to the sorbent). Alkyl and aromatic $\mathrm{C}-\mathrm{C}$ bonds (detected in the range 284.4-284.7 eV) represent higher fractions in HABA-based sorbent than in ABA-based material (in the ranges $44-52 \%$ and $33-46 \%$, respectively). Sulfur element was also observed; the assignments of four contributions corresponding to $\mathrm{S} 2 p_{1 / 2}$ and $\mathrm{S} 2 p_{3 / 2}$ characterize the presence of sulfide/disulfide compounds (S $2 p_{3 / 2}$ : around $162.6 \mathrm{eV}$ and $\mathrm{S} 2 p_{1 / 2}$ : around $163.7 \mathrm{eV}$ ) and sulfate compounds (S $2 p_{3 / 2}$ : around $168.4 \mathrm{eV}$ and $\mathrm{S} 2 p_{1 / 2}$ : around $169.5 \mathrm{eV}$ ); they are associated to Pd element by formation of sulfides and sulfates. The fraction of the different forms depends on the support and the treatment (reduction, catalyst reuse). For HABA-based materials, the three materials show the presence of both sulfide and sulfate species; the proportion of sulfate becomes slightly higher in the reduced material (Table S2, see Supplementary Material Section). For ABA-based materials, Pd-loaded sorbent show the co-existence of sulfide $(2 / 3)$ and sulfate $(1 / 3)$ forms, while after reduction and during catalyst reuse, the sulfide species disappeared.

For catalytic application the oxidation state of Pd is of critical importance. The Pd $3 d_{5 / 2}$ signal can be used for characterizing the potential reducing power of the catalysts. Fig. S18 (see Supplementary Material Section) allows identifying a series of differences. Three signals can be detected at around $334.9-335.6 \mathrm{eV}, 336.2 \mathrm{eV}$ and $337.8 \mathrm{eV}$ corresponding to $\mathrm{Pd}(0)$ and $\mathrm{Pd}(\mathrm{II})$ [51] under the forms of sulfide or amino complex and sulfate, respectively. This surface analysis differs from the conclusion of the SEM-EDX characterization that showed the correlation in the distribution of $\mathrm{Cl}$ and Pd elements in the whole mass of the sorbent. Substantial differences are observed between HABAbased and ABA-based materials: Pd(II) sorbent is associated to sulfate and sulfide compounds with different fractions: 76/24 fractions for HABA sorbent contrary to $71 / 29$ fractions for ABA. After chemical reduction with hydrazine hydrate for HABA-based catalyst, Pd is only partially reduced (to 50\%); the sulfide form of Pd(II) remains almost constant while the residual fraction of Pd(II) associated to sulfate decreases to $28 \%$. This means that Pd-sulfide is relatively more stable than sulfate-form and that the reduction of Pd(II) is incomplete. In the case of ABA-based catalyst, the fraction of reduced Pd increases up to $71 \%$ while the sulfate-based fraction of Pd(II) remains almost constant (close to $29 \%$ ). In this case the sulfide form has completely disappeared and it is supposed that the processing with hydrogen produced by acid reaction on zinc power was more efficient for reducing this Pd(II) fraction. This is the reciprocal to the result obtained with HABA. Despite this higher efficiency in Pd(II) reduction, ABA catalyst, as mentioned above, does not show better catalytic performance than HABA catalyst. This could be explained by the aggregates of Pd particles on ABA catalyst (observed from SEM images). When recycled, the fractions of $\operatorname{Pd}(0)$ on the materials decrease to around $43-45 \%$ for the two catalysts with formation of Pd-sulfate forms. The speciation of Pd on the catalyst may have a strong impact on catalytic activity and the presence of sulfurbased compounds may be considered as a poison for some catalytic applications [52,53].

HABA/PEI sorbent is more efficient for Pd(II) binding as already demonstrated during the study of metal sorption; the XPS analysis indicates that Pd(II) is probably associated to sulfide or amino complex and sulfate with different fractions depending on the sorbent (and/or the process used for metal reduction in the case of catalysts). Palladium reduction using the hydrazine hydrate (in alkaline condition) (for HABA-PEI/Pd) and the hydrogen reduction $\left(\mathrm{H}_{2} \mathrm{SO}_{4} / \mathrm{Zn}\right.$, for ABA/PEI$\mathrm{PD})$ processes does not allow completely reducing $\operatorname{Pd}(\mathrm{II})$ to $\operatorname{Pd}(0)$ : 
reduction efficiency ranges between 50 and $71 \%$; the presence of sulfide/sulfate seems to affect the reduction efficiency. When re-used, the effective fraction of active $\operatorname{Pd}(0)$ decreases. It is noteworthy that HABAbased materials appear to be more stable than ABA-based catalyst. The incomplete reduction of $\mathrm{Pd}(\mathrm{II})$ and the resistance to mass transfer should be the causes of the low catalytic activity. While the slight decrease of effective $\operatorname{Pd}(0)$ fraction when re-used may explain the weakly decreasing catalytic activity. Improving Pd(II) reduction and mass transfer would contribute to improving catalytic performance and getting closer to the performances of alternative materials.

\section{Conclusions}

A new sorbent, homogenously PEI-functionalized algal beads (HABA/PEI), was prepared by pre-mixing PEI, alginate and algal biomass before crosslinking using a solution containing both $\mathrm{CaCl}_{2}$ and glutaraldehyde (GA). The heterogeneous beads loaded with the same amount of PEI-GA particles (ABA/PEI) were prepared as a reference. These two kinds of beads were compared as sorbents for Pd(II) recovery and as supported catalysts for 3-nitrophenol reduction after reducing loaded $\mathrm{Pd}(\mathrm{II})$ into $\mathrm{Pd}(0)$. The results suggest that the $\mathrm{Pd}(\mathrm{II})$ sorption capacity and the stability of HABA/PEI is higher than ABA/PEI beads. The sorption isotherms and uptake kinetics at $\mathrm{pH} 1$ are well fitted by Langmuir model and Crank equation, respectively. The uniform dispersion of PEI makes sorption sites on functional material (PEI) more accessible. This contributes to increase maximum sorption capacity for HABA/PEI beads compared with ABA/PEI beads. However, this structure decreases the mass transfer property of HABA/PEI beads: the diffusion coefficient calculated with the Crank equation for HABA/PEI is lower than that for ABA/PEI beads. For catalytic investigation, hydrazine hydrate was chosen for reducing Pd(II) to Pd(0) on HABA/PEI, while Pd(II)-loaded ABA/PEI beads (degraded in hydrazine solution under $60^{\circ} \mathrm{C}$ ) were treated with hydrogen gas, generated in situ by the reaction of sulfuric acid and zinc particles. SEM images show that Pd nanoparticles are well dispersed on HABA/PEI, while on ABA/PEI beads, some aggregates of the nanoparticles are observed. Both catalysts show similar catalytic performance for 3-NP reduction. But the lower Pd(II) concentration required for metal loading process and higher stability shown in reuse experiments suggest a greater potential of HABA/PEI-Pd catalyst for practical applications.

However, the catalytic activity of Pd nanoparticles supported on HABA/PEI beads is still lower than those of more conventional catalysts: this is probably due to poor mass transfer property. HABA/PEI-Pd catalyst is environmental friendly and relatively low-cost. Moreover, easily recoverable property and high stability also make this catalyst attractive.

Further research will focus on the optimization of Pd loaded on the catalysts and its reduction procedure (combination of reducing reagents). Another factor worthy of exploring is to change the shape of the supports. We are currently working on the synthesis of highly porous foams that exhibit outstanding percolating characteristics. This alternative conditioning of the material is expected to decrease the mass transfer resistance for improving reaction rate.

XPS analysis confirmed the higher Pd content in the catalyst and that HABA/PEI-Pd material is more stable than ABA/PEI-Pd catalyst along metal reduction and catalyst re-use. More characterization using techniques are required, such as transmission electron microscopy (TEM) to have a better evaluation of the distribution and particle size of the nanoparticles.

\section{Acknowledgments}

S. Wang acknowledges the China Scholarship Council (CSC, Grant $\mathrm{N}^{\circ}$ 20156660002) for providing PhD fellowship. T. Vincent and E. Guibal acknowledge European Union's Seventh Framework Programme (FP7/2007-2013) since these results are indirectly derived from a research project (BIOMETAL-DEMO) funded by the FP7 Programme managed by Research Executive Agency (http://ec.europa.eu/ research/rea) under Grant $\mathrm{N}^{\circ}$ 699101. E. Rodríguez-Castellón acknowledges Ministerio de Economía y Competitividad of Spain (CTQ2015-68951-C3-3-R and FEDER Funds). Authors thank JeanClaude Roux (IMT Mines Alès, C2MA) for his technical support for SEM and SEM-EDX analyses.

\section{Appendix A. Supplementary data}

Supplementary data related to this article can be found at https:// doi.org/10.1016/j.matchemphys.2018.09.021.

\section{References}

[1] B. Kunwar, S.D. Deilami, L.E. Macaskie, J. Wood, P. Biller, B.K. Sharma, Nanoparticles of Pd supported on bacterial biomass for hydroprocessing crude biooil, Fuel 209 (2017) 449-456.

[2] F. Di Natale, M. Orefice, F. La Motta, A. Erto, A. Lancia, Unveiling the potentialities of activated carbon in recovering palladium from model leaching solutions, Separ. Purif. Technol. 174 (2017) 183-193.

[3] V.-P. Dinh, N.-C. Le, L.A. Tuyen, N.Q. Hung, V.-D. Nguyen, N.-T. Nguyen, Insight into adsorption mechanism of lead(II) from aqueous solution by chitosan loaded $\mathrm{MnO}_{2}$ nanoparticles, Mater. Chem. Phys. 207 (2017) 294-302.

[4] S. Cataldo, A. Gianguzza, A. Pettignano, Sorption of Pd (II) ion by calcium alginate gel beads at different chloride concentrations and pH. A kinetic and equilibrium study, Arab. J. Chem. 9 (2016) 656-667.

[5] S. Wang, T. Vincent, J.-C. Roux, C. Faur, E. Guibal, Innovative conditioning of algalbased sorbents: macro-porous discs for palladium sorption, Chem. Eng. J. 325 (2017) 521-532.

[6] N. Mnasri, J.L. Nyalosaso, S. Kachbouri, J. Zajac, E. Elaloui, C. Charnay, Preparation and characterization of gold nanoparticles and nanowires loaded into rod-shaped silica by a one-step procedure, Solid State Sci. 63 (2017) 23-29.

[7] J.D. Kim, M.Y. Choi, H.C. Choi, Catalyst activity of carbon nanotube supported Pd catalysts for the hydrogenation of nitroarenes, Mater. Chem. Phys. 173 (2016) 404-411.

[8] E. Baldikova, K. Pospiskova, M. Safarikova, I. Safarik, Non-woven fabric supported manganese dioxide microparticles as a low-cost, easily recoverable catalyst for hydrogen peroxide decomposition, Mater. Chem. Phys. 203 (2018) 280-283.

[9] T. Vincent, E. Guibal, Chitosan-supported palladium catalyst. 1. Synthesis procedure, Ind. Eng. Chem. Res. 41 (2002) 5158-5164.

[10] Z. Dong, X. Le, Y. Liu, C. Dong, J. Ma, Metal organic framework derived magnetic porous carbon composite supported gold and palladium nanoparticles as highly efficient and recyclable catalysts for reduction of 4-nitrophenol and hydrodechlorination of 4-chlorophenol, J. Mater. Chem. 2 (2014) 18775-18785.

[11] A.B. Dongil, L. Pastor-Pérez, J.L. Fierro, N. Escalona, A. Sepúlveda-Escribano, Synthesis of palladium nanoparticles over graphite oxide and carbon nanotubes by reduction in ethylene glycol and their catalytic performance on the chemoselective hydrogenation of para-chloronitrobenzene, Appl. Catal. Gen. 513 (2016) 89-97.

[12] D. Kumar, L.K. Pandey, J. Gaur, Metal sorption by algal biomass: from batch to continuous system, Algal Res 18 (2016) 95-109.

[13] J. He, J.P. Chen, A comprehensive review on biosorption of heavy metals by algal biomass: materials, performances, chemistry, and modeling simulation tools, Bioresour. Technol. 160 (2014) 67-78.

[14] I. Anastopoulos, G.Z. Kyzas, Progress in batch biosorption of heavy metals onto algae, J. Mol. Liq. 209 (2015) 77-86.

[15] S. Wang, T. Vincent, J.-C. Roux, C. Faur, E. Guibal, Pd (II) and Pt (IV) sorption using alginate and algal-based beads, Chem. Eng. J. 313 (2017) 567-579.

[16] M.M. Ayad, W.A. Amer, M.G. Kotp, Magnetic polyaniline-chitosan nanocomposite decorated with palladium nanoparticles for enhanced catalytic reduction of 4-nitrophenol, Mol. Catal. 439 (2017) 72-80.

[17] J. Fu, S. Wang, J. Zhu, K. Wang, M. Gao, X. Wang, Q. Xu, Au-Ag bimetallic nanoparticles decorated multi-amino cyclophosphazene hybrid microspheres as enhanced activity catalysts for the reduction of 4-nitrophenol, Mater. Chem. Phys. 207 (2018) 315-324.

[18] F. Ramírez-Crescencio, R. Redón, A. Herrera-Gomez, G. Gomez-Sosa, M. BravoSanchez, A.-L. Fernandez-Osorio, Facile obtaining of Iridium(0), Platinum(0) and Platinum(0)-Iridium(0) alloy nanoparticles and the catalytic reduction of 4-nitrophenol, Mater. Chem. Phys. 201 (2017) 289-296.

[19] J. Gustafson, Visual-minteq, Version 3.0, (2010).

[20] K. Shah, S. Bhagat, D. Varade, S. Singh, Novel synthesis of polyoxyethylene cholesteryl ether coated Fe-Pt nanoalloys: a multifunctional and cytocompatible bimetallic alloy exhibiting intrinsic chemical catalysis and biological enzyme-like activities, Colloid. Surface. 553 (2018) 50-57.

[21] P. Dauthal, M. Mukhopadhyay, Biofabrication, characterization, and possible bioreduction mechanism of platinum nanoparticles mediated by agro-industrial waste and their catalytic activity, J. Ind. Eng. Chem. 22 (2015) 185-191.

[22] Z. Dong, X. Le, C. Dong, W. Zhang, X. Li, J. Ma, Ni@ Pd core-shell nanoparticles modified fibrous silica nanospheres as highly efficient and recoverable catalyst for reduction of 4-nitrophenol and hydrodechlorination of 4-chlorophenol, Appl. Catal. B Environ. 162 (2015) 372-380. 
[23] M. Abbasi, R. Amiri, A.-K. Bordbar, E. Ranjbakhsh, A.-R. Khosropour, Improvement of the stability and activity of immobilized glucose oxidase on modified iron oxide magnetic nanoparticles, Appl. Surf. Sci. 364 (2016) 752-757.

[24] M. Naebe, J. Wang, A. Amini, H. Khayyam, N. Hameed, L.H. Li, Y. Chen, B. Fox, Mechanical property and structure of covalent functionalised graphene/epoxy nanocomposites, Sci. Rep. 4 (2014) 4375.

[25] I.S. Tan, K.T. Lee, Immobilization of $\beta$-glucosidase from Aspergillus Niger on к-carrageenan hybrid matrix and its application on the production of reducing sugar from macroalgae cellulosic residue, Bioresour. Technol. 184 (2015) 386-394.

[26] M.P. Hofmann, A.M. Young, U. Gbureck, S.N. Nazhat, J.E. Barralet, FTIR-monitoring of a fast setting brushite bone cement: effect of intermediate phases, J. Mater. Chem. 16 (2006) 3199-3206.

[27] J.E.M. Theras, D. Kalaivani, D. Jayaraman, V. Joseph, Growth and spectroscopic, thermodynamic and nonlinear optical studies of L-threonine phthalate crystal, J. Cryst. Growth 427 (2015) 29-35.

[28] G. Xiaohong, C.Q. Yang, FTIR spectroscopy study of the formation of cyclic anhydride intermediates of polycarboxylic acids catalyzed by sodium hypophosphite, Textil. Res. J. 70 (2000) 64-70.

[29] T.-L. Lin, H.-L. Lien, Effective and selective recovery of precious metals by thiourea modified magnetic nanoparticles, Int. J. Mol. Sci. 14 (2013) 9834-9847.

[30] X. Gao, Y. Zhang, Y. Zhao, Biosorption and reduction of Au (III) to gold nanoparticles by thiourea modified alginate, Carbohydr. Polym. 159 (2017) 108-115.

[31] K.-M. Khoo, Y.-P. Ting, Biosorption of gold by immobilized fungal biomass, Biochem. Eng. J. 8 (2001) 51-59.

[32] M.S. Shoichet, R.H. Li, M.L. White, S.R. Winn, Stability of hydrogels used in cell encapsulation: an in vitro comparison of alginate and agarose, Biotechnol. Bioeng. 50 (1996) 374-381.

[33] Q. Ricoux, V. Bocokić, J. Méricq, D. Bouyer, S. Zutphen, C. Faur, Selective recovery of palladium using an innovative functional polymer containing phosphine oxide, Chem. Eng. J. 264 (2015) 772-779.

[34] I. de Vargas, L.E. Macaskie, E. Guibal, Biosorption of palladium and platinum by sulfate-reducing bacteria, J. Chem. Technol. Biotechnol. 79 (2004) 49-56.

[35] A. Butewicz, K.C. Gavilan, A. Pestov, Y. Yatluk, A. Trochimczuk, E. Guibal, Palladium and platinum sorption on a thiocarbamoyl-derivative of chitosan, J. Appl. Polym. Sci. 116 (2010) 3318-3330.

[36] T.S. Choong, T. Chuah, Comment on "Separation of vitamin E from palm fatty acid distillate using silica: I. Equilibrium of batch adsorption by BS Chu et al. [Journal of Food Engineering 62 (2004) 97-103]”, J. Food Eng. 67 (2005) 379.

[37] H.N. Tran, S.-J. You, A. Hosseini-Bandegharaei, H.-P. Chao, Mistakes and inconsistencies regarding adsorption of contaminants from aqueous solutions: a critical review, Water Res. 120 (2017) 88-116.

[38] Y. Marcus, Ion Properties, Marcel Dekker, Inc., New York, NY, 1997, p. 259.

[39] S. Chaudhari, G. Deshmukh, Fluidization effect on removal and recovery of palladium (II) from wastewater by chelated ion exchange resin, Chem. Eng. Commun. (2015), https://doi.org/10.1080/00986445.2014.880423.
[40] H.A. Choi, H.N. Park, S.W. Won, A reusable adsorbent polyethylenimine/polyvinyl chloride crosslinked fiber for Pd (II) recovery from acidic solutions, J. Environ. Manag. 204 (2017) 200-206.

[41] X. Gu, W. Qi, X. Xu, Z. Sun, L. Zhang, W. Liu, X. Pan, D. Su, Covalently functionalized carbon nanotube supported Pd nanoparticles for catalytic reduction of 4 nitrophenol, Nanoscale 6 (2014) 6609-6616.

[42] H. Li, L. Han, J. Cooper-White, I. Kim, Palladium nanoparticles decorated carbon nanotubes: facile synthesis and their applications as highly efficient catalysts for the reduction of 4-nitrophenol, Green Chem. 14 (2012) 586-591.

[43] S. Harish, J. Mathiyarasu, K. Phani, V. Yegnaraman, Synthesis of conducting polymer supported Pd nanoparticles in aqueous medium and catalytic activity towards 4-nitrophenol reduction, Catal. Lett. 128 (2009) 197.

[44] Y. Xue, X. Lu, X. Bian, J. Lei, C. Wang, Facile synthesis of highly dispersed palladium/polypyrrole nanocapsules for catalytic reduction of p-nitrophenol, J. Colloid Interface Sci. 379 (2012) 89-93.

[45] X. Le, Z. Dong, X. Li, W. Zhang, M. Le, J. Ma, Fibrous nano-silica supported palladium nanoparticles: an efficient catalyst for the reduction of 4-nitrophenol and hydrodechlorination of 4-chlorophenol under mild conditions, Catal. Commun. 59 (2015) 21-25.

[46] N.A. Travlou, E. Rodríguez-Castellón, T.J. Bandosz, Sensing of $\mathrm{NH}_{3}$ on heterogeneous nanoporous carbons in the presence of humidity, Carbon 100 (2016) 64-73.

[47] D. Briggs, M. Seah, Practical Surface Analysis by Auger and X-ray Photoemission Spectroscopies, John Wiley, New York, 1983.

[48] M. Seredych, K. László, E. Rodríguez-Castellón, T.J. Bandosz, S-doped carbon aerogels/GO composites as oxygen reduction catalysts, J. Energy Chem. 25 (2016) 236-245.

[49] C.B. Vidal, M. Seredych, E. Rodríguez-Castellón, R.F. Nascimento, T.J. Bandosz, Effect of nanoporous carbon surface chemistry on the removal of endocrine disruptors from water phase, J. Colloid Interface Sci. 449 (2015) 180-191.

[50] M. Algarra, M. Pérez-Martín, M. Cifuentes-Rueda, J. Jiménez-Jiménez, J.E. da Silva, T. Bandosz, E. Rodriguez-Castellon, J.L. Navarrete, J. Casado, Carbon dots obtained using hydrothermal treatment of formaldehyde. Cell imaging in vitro, Nanoscale 6 (2014) 9071-9077.

[51] E. Vilarrasa-García, A. Infantes-Molina, R. Moreno-Tost, E. Rodríguez-Castellón, A. Jiménez-López, C.L. Cavalcante Jr., D.C. Azevedo, Thiophene adsorption on microporous activated carbons impregnated with $\mathrm{PdCl}_{2}$, Energy Fuel. 24 (2010) 3436-3442.

[52] L. Lin, T. Zhang, H. Liu, J. Qiu, X. Zhang, In situ fabrication of a perfect Pd/ZnO@ ZIF-8 core-shell microsphere as an efficient catalyst by a ZnO support-induced ZIF8 growth strategy, Nanoscale 7 (2015) 7615-7623.

[53] Y. Shu, T. Aikebaier, X. Quan, S. Chen, H. Yu, Selective catalytic reaction of $\mathrm{NO}_{\mathrm{x}}$ with $\mathrm{NH}_{3}$ over $\mathrm{Ce}-\mathrm{Fe} / \mathrm{TiO}_{2}$-loaded wire-mesh honeycomb: resistance to $\mathrm{SO}_{2}$ poisoning, Appl. Catal. B Environ. 150 (2014) 630-635. 